\title{
Assessment of pilot health project outcome indicators: West Bank/Gaza
}

\author{
Laila Nawar \\ Dale Huntington \\ Ibrahim Kharboush \\ Nancy Ali \\ Mahmoud Shaheen
}

Follow this and additional works at: https://knowledgecommons.popcouncil.org/departments_sbsr-rh

Part of the Demography, Population, and Ecology Commons, International Public Health Commons, Maternal and Child Health Commons, and the Women's Health Commons How does access to this work benefit you? Let us know!

\section{Recommended Citation}

Nawar, Laila, Dale Huntington, Ibrahim Kharboush, Nancy Ali, and Mahmoud Shaheen. 2003. "Assessment of pilot health project outcome indicators: West Bank/Gaza," FRONTIERS Final Report. Washington, DC: Population Council. 


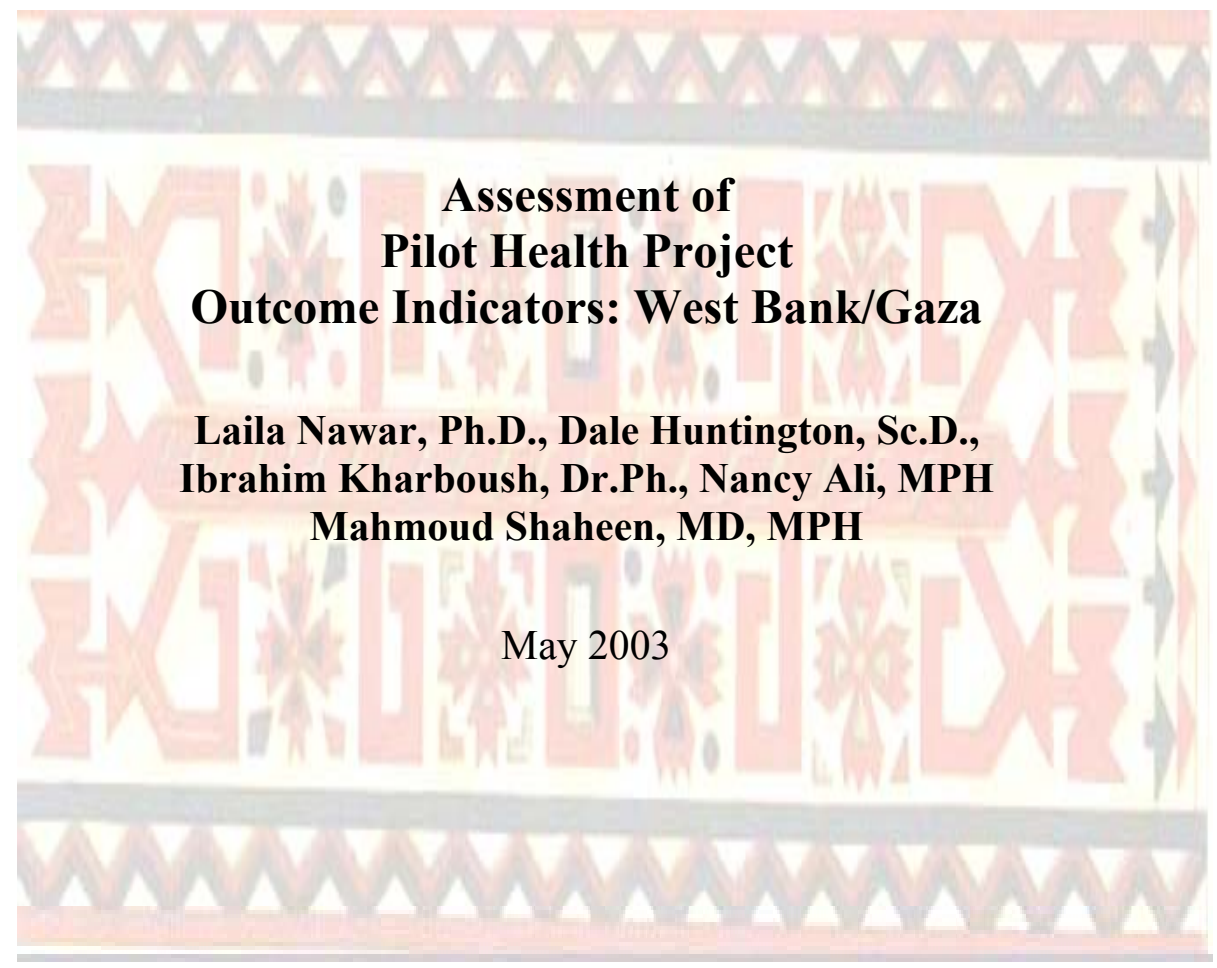

This study was funded by the U.S. AGENCY FOR INTERNATIONAL DEVELOPMENT (USAID) under the terms of Cooperative Agreement number HRN-A-00-98-00012-00 and Population Council Subcontract Number CI01.51A. The opinions expressed herein are those of the authors and do not necessarily reflect the views of USAID. 


\section{CONTENTS}



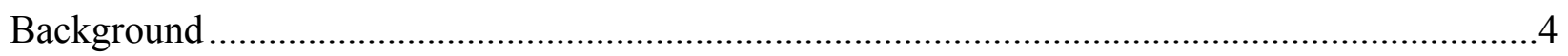

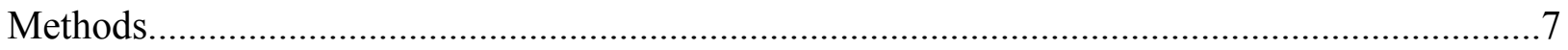

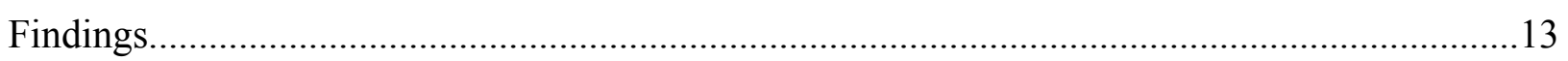

Post-Intervention Levels of Key Outcome Indicators for the PHP..............................................19

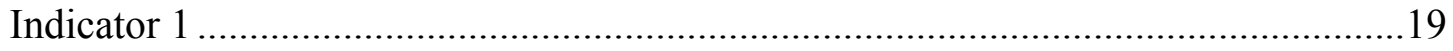

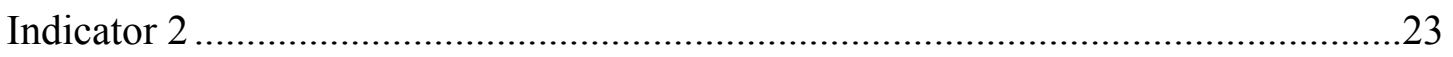

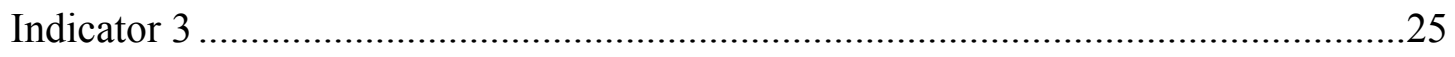

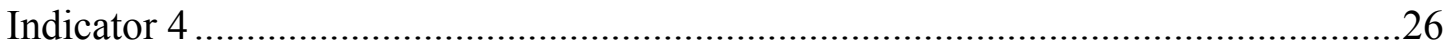

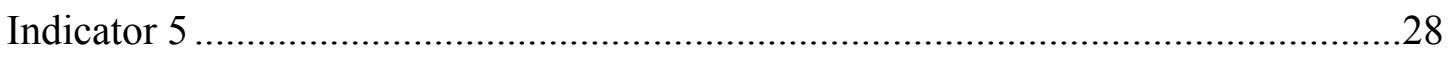

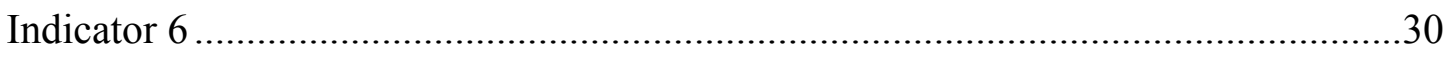

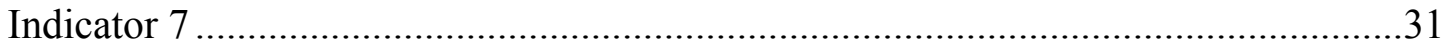



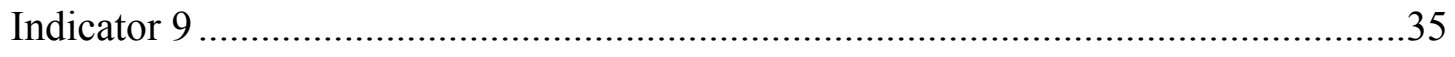

Selected Insights into Quality of Care and Accessibility................................................................

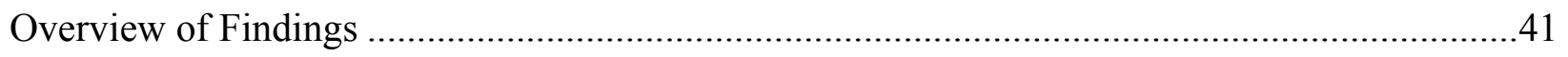

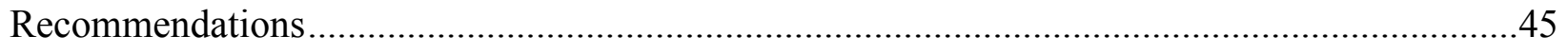






\section{TABLES AND FIGURES}

Table 1: Location, Affiliation and Staffing of the PHP Project Clinics in the Post-test Survey .....8

Table 2: Sample Distribution Results by Clinic and Reasons for Visiting the Clinic ....................10

Table 3: Selected Demographic and Socio-Economic Characteristics of Women and their Husbands in the Pre-test and Post-test.......................................................................12

Table 4: Profile of Women's Living Conditions .......................................................................

Table 5: Women's Reproductive Health History Profile................................................................. 15

Table 6: Desire for Additional Children by Number of Living Children and Living Sons............15

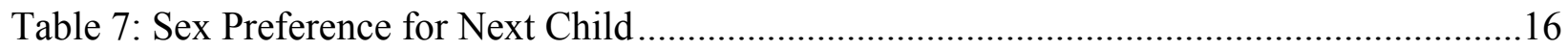

Table 8: Selected Background Characteristics of Nurses and CHWs in PHP Clinics.....................16

Table 9: Selected Background Characteristics of Physicians in PHP Clinics ................................17

Table 10: Proxy Indicators on the First Outcome Indicator .......................................................

Table 11: Antenatal Care Experience of Women Receiving Postpartum Care .............................20

Table 12: Use of Obstetrical Service among PHP Postpartum Clients .........................................21

Table 13: Postpartum Women Who Came to PHP Clinics to Receive FP Counseling and

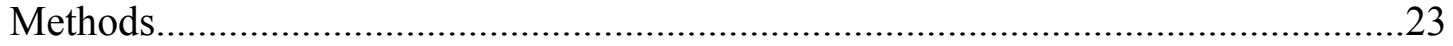

Table 14: Past and Current Use of Family Planning Methods.......................................................24

Table 15: Current Use of Family Planning Methods by Number of Living Children ....................25

Table 16: Percent of Antenatal Women Who Were Informed by Service Providers About ANC Warning Signs.......................................................................................................2

Table 17: Antenatal Women Reporting Experiencing ANC Warning Signs During Pregnancy

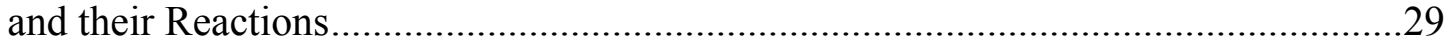

Table 18: Postpartum Women Reporting Experiencing PP Warning Signs and their Reactions..29

Table 19: Knowledge and Practice of Breast-Self Examination, Antenatal and Postpartum

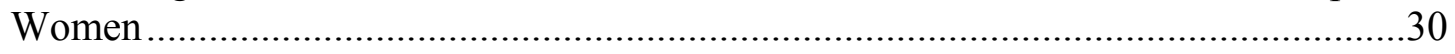

Table 20: Pap Smear Tests Among Antenatal Clients (35 years and above) .................................30

Table 21: Clients Reports on Husbands' Involvement ..................................................................

Table 22: Percent Distribution of Number of Tasks Performed by the Health Care Providers During Antenatal Examination 
Table 23: Percent Distribution of Number of Tasks Performed by the Health Care Providers During Postpartum Examination

Table 24: Nurses' and CHWs' Report on the Information they Usually Provide to New Family Planning Clients .33

Table 25: Reports of Service Providers on the Training Provided by CDPHC under PHP .34

Table 26: Reports of Service Providers on the BCC Materials Developed for the PHP .34

Table 27: Percent of ANC Clients Who Received Information from Health Providers on the Specified Items 36

Table 28: Percent of Postpartum Women Reporting Receiving the Specified Information from Health Providers. .36

Table 29: Selected Aspects of Accessibility to PHP Clinics .38

Figure 1: Reasons for Clinic Visit .18

Figure 2: Postpartum Clients Checked at the Visited Clinic: Are you coming today for a health exam for yourself or the baby? .20

Figure 3: Knowledge of Family Planning Methods Among Ever PHP Married Women (\%) ......24

Figure 4: Percentage Distribution of Current Family Users by Number of Living Children .........26

Figure 5: Percent of Postpartum Women Who Were Informed About Postpartum Warning Signs $(\%)$ .27

Figure 6: Total Knowledge Score of ANC and PP Women on ANC, PP and Newborn Warning Signs Items $(\%)$....... .28

Figure 7: Percent of Obstetric History Items Inquired About by the Health Care Providers During the Antenatal Visit .32

Figure 8: Percent of ANC Women Who Reported Being Told About Selected Aspects and Next Steps by Health Providers.

Figure 9: Among Women Who Ever Received Contraceptives from the Clinic, Percent Informed About:

Figure 10: Quality of Care: Client-Provider Interaction .39

Figure 11: Selected Indicators of Quality of Care .39

Figure 12: Women's Reports on Physical Changes of Clinic and Services Offered during past 12-18 months 


\section{ACRONYMS}

$\begin{array}{ll}\text { ANC } & \text { Antenatal Care } \\ \text { BCC } & \text { Behavior Change Communication } \\ \text { CDPHC } & \text { Center for Development in Primary Health Care } \\ \text { CHW } & \text { Community Health Worker } \\ \text { HDIP } & \text { Health, Development, Information and Policy Institute } \\ \text { IUD } & \text { Intra Uterine Device } \\ \text { IVCHS } & \text { Improved Village and Community Health Services Project } \\ \text { LAM } & \text { Lactational Amenorrhea Method } \\ \text { MCH } & \text { Maternal and Child Health } \\ \text { MIS } & \text { Management Information System } \\ \text { MOH } & \text { Ministry of Health } \\ \text { NGO } & \text { Non-governmental Organization } \\ \text { PCBS } & \text { Palestinian Central Bureau of Statistics } \\ \text { PFS } & \text { The Patients Friends Society } \\ \text { PHP } & \text { Pilot Health Project } \\ \text { PP } & \text { Postpartum Care } \\ \text { SES } & \text { Socio-economic Status } \\ \text { TFR } & \text { Total Fertility Rate } \\ \text { UHWC } & \text { The Union of Health Work Committees } \\ \text { UPMRC } & \text { The Union of Palestinian Medical Relief Committees } \\ \text { USAID } & \text { United States Agency for International Development } \\ \text { WHO } & \text { World Health Organization } \\ & \text { ThO }\end{array}$




\section{EXECUTIVE SUMMARY}

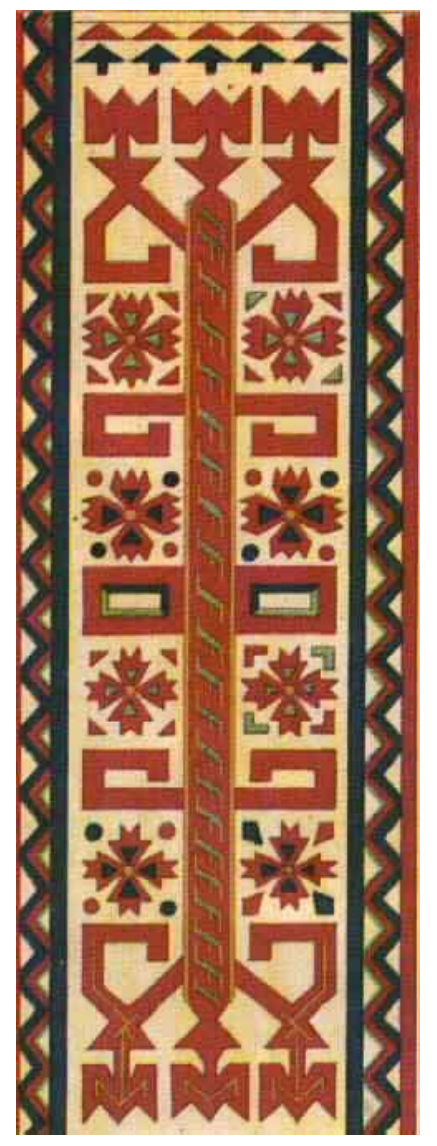

The lack of care provided to women and newborns during the postpartum period creates a serious gap in the primary health care system of the West Bank and Gaza. While a large percentage of women receive some prenatal care, very few return to health facilities for postpartum follow-up visits. As part of an effort to improve the health status of Palestinian women and their children in the West Bank and Gaza, the United States Agency for International Development (USAID), in collaboration with the Palestinian Ministry of Health $(\mathrm{MOH})$ and seven partners, designed and funded a 28 -month pilot activity that is expected to have a significant impact on the health of women and children. The goal of this Pilot Health Project (PHP) is to upgrade antenatal and postpartum services in 27 primary health care clinics in three areas of the West Bank and Gaza. The project interventions include establishing a basic package of quality antenatal and postpartum care services aimed at improving the health-giving practices of providers and health-seeking behavior of families.

A single cross-sectional study was conducted by the Health, Development, Information and Policy Institute (HDIP) between May and August 2000 in order to determine the baseline measures for the PHP's key outcome indicators among health care providers and clients in the PHP clinics. Information was collected on providers' technical knowledge and reported clinical practices, as well as clients' knowledge and practices related to antenatal care, postpartum visits, care of the newborn, family planning, breast-self examination, and Pap smear tests.

Alpha International for Research, Polling and Informatics took responsibility for conducting the post-test survey. Data collection for the post-test took place in the West Bank and Gaza between October and December 2001. The sample for the women's post-test survey was 1,070 (the pretest sample was 792). The objective of the post-test survey was to evaluate the impact of the interventions introduced by comparing changes between the pre-test and post-test survey on the PHP key outcome indicators. The post-test survey utilized the same cross-sectional study design and data collection methods that the pre-test survey employed. This report presents the findings of this survey.

The lifetime of the PHP project was relatively short (28 months) to both institute and sustain complex interventions. Also, the onset of Al Aqsa Intifada in September 2000 has caused complete closures of some of the Palestinian towns and villages and impacted the possibility of carrying out original work plans. Despite these challenges, the post-test study has reflected many positive achievements.

A total of 49 nurses and community health workers (CHWs) were interviewed in the post-test survey ( 45 nurses and CHWs were interviewed in the pre-test). A total of nine physicians were 
identified working at PHP clinics in both pre-test and post-test surveys, and each of them was interviewed in both surveys (not all service providers interviewed in the pre-test and post-test survey were the same).

The findings indicated a significant increase in the proportion of postpartum care and family planning visits between the pre- and post-test surveys. The proportion of postpartum visits doubled from 2.1 percent in the pre-test to 4.2 percent in the post-test. Family planning visits increased almost two-and-a-half fold between the two surveys.

About 32 percent of the women reported current use of a family planning method in the post-test compared to only about 14 percent in the pre-test. Also, low parity women currently using any family planning method increased from only about 7 percent in the pre-test to about 29 percent in the post-test. All these differences are statistically significant.

There have been modest improvements in women's knowledge about antenatal care (ANC) and postpartum (PP) warning signs items. Yet, the percentage of antenatal women who reported knowledge at least 10 antenatal warning signs items increased from 9 percent in the pre-test to about 20 percent in the post-test. Also, the percentage of postpartum women reporting knowledge of at least five postpartum warning sign items increased from about 4 percent in the pre-test to about 24 percent in the post-test.

A range of antenatal women experienced one or more of the ANC warning signs during their pregnancies (5-25\%). Almost all of these women (93\% in pre-test and $94 \%$ in post-test) sought treatment of this health condition, and about four-fifths received treatment. Also, despite the small number of cases of postpartum women, the findings from this study indicate that all women who experienced postpartum warning signs sought treatment in both pre-test and posttest surveys.

A smaller proportion of women in the post-test survey compared with the pre-test survey $(27 \%$ versus $35 \%$ ) reported being told by service providers how to conduct breast-self examination on a regular basis. Yet, of those who received this information, 60 percent of women in the post-test reported that their source of knowledge was the PHP clinic, compared to 21 percent in the pretest. Additionally, more women in the post-test survey reported conducting this self-examination on a regular basis compared with pre-test survey (about $60 \%$ versus $41 \%$ ). These differences are statistically significant and indicate the positive impact of the PHP.

Men continued to be involved in their wives' reproductive health. Husbands' beliefs in the importance of antenatal care for their wives and their encouragement for ANC visits were almost universal in both pre-test and post-test surveys. Furthermore, an overwhelming majority of women in both surveys (92\%) reported discussing the use of family planning methods with their husbands.

Substantially more antenatal women reported in the post-test that they were asked by health providers about all nine of the obstetric history items (72\%), compared to only 39 percent in the pre-test. Also, more antenatal and postpartum women reported in the post-test that health providers conducted more complete health examinations, compared with the pre-test. In addition, 
the percentage of nurses and CHWs who reported providing all four of the counseling items for family planning methods increased from about 31 percent in the pre-test to about 41 percent in the post-test. This reflects the substantial improvements made by the PHP in the provision of information by nurses and CHWs.

The percentage of ANC women who reported receiving information on all 12 of the ANC information items increased from less than 3 percent in the pre-test to 13 percent in the post-test. Also, the percentage of postpartum women who reported receiving information on all nine postpartum items increased from less than 4 percent in the pre-test to 22 percent in the post-test. These differences are statistically significant, and reveal that despite impressive gains, there is still room for further improvements.

Although baseline indicators of quality of care were already high, the PHP achieved additional positive gains. More women in the post-test reported that the physician explained procedures to them (post 97\% versus pre 91\%) and that they were able to discuss all their concerns with them (post 97\% versus pre 91\%).

Also, most of the clients noticed changes made at the clinics during the intervention period including clinic renovations, additional equipment procurement, additional services introduced, and behavior change communication (BCC) materials developed and distributed to clinics and clients. These changes encouraged more visits to PHP clinics (as reported by $94 \%$ of women).

Based on the findings reflected by the study, a number of recommendations were made that need to be followed up and implemented by the Improved Village and Community Health Services Project. These include the need for establishing referral mechanisms to promote wider coverage of essential postpartum care, the need for providing continuous training for service providers, and the importance of raising public awareness about the health benefits of spacing births. The study also recommended integrating breast-self examination and cervical cancer screening into routine primary health care services. 


\section{BACKGROUND}

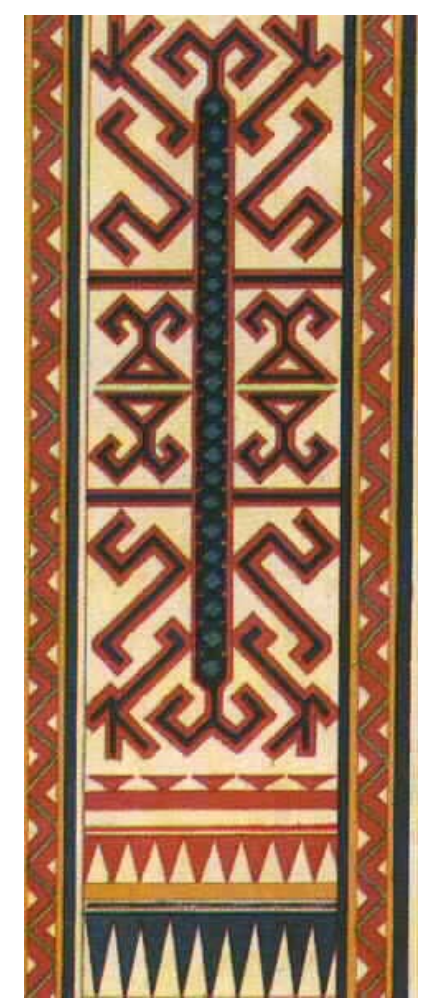

\section{The Reproductive Health Situation of Palestinian Women}

The reproductive health situation of Palestinian women is characterized by a very high fertility rate, including early childbearing and short birth intervals. The total fertility rate (TFR) is 5.93 (5.52 in the West Bank and 6.81 in the Gaza Strip), and it is highest among rural women and women with less than a secondary education. According to a recent health survey by the Palestinian Central Bureau of Statistics (PCBS) (2000) $)^{1}$, approximately one in five women $(21.7 \%)$ had their first child before the age of 18 , and about one-half of Palestinian women $(50.3 \%)$ had birth intervals shorter than 18 months. Antenatal care coverage by skilled providers is high $(95.6 \%)$, and 95.2 percent of women complete at least three antenatal visits. Therefore, it appears that the majority of the women surveyed met the minimum of four antenatal visits recommended by the World Health Organization $(\mathrm{WHO})^{2}$. However, there is little data about the actual content of these visits, and the quality of care for pregnant women needs further investigation. In contrast, the coverage for postpartum care is low, with only about one in five women receiving postpartum care ${ }^{1}$. As in antenatal care, little data exist on the content of postpartum services.

Palestinian women exhibit a high level of knowledge of family planning methods, with over 99 percent of ever-married and currently married women reporting knowledge of a modern contraceptive method ${ }^{1}$. However, there appears to be a gap between knowledge and practice. The contraceptive prevalence rate is 36.7 percent for modern methods (the majority of whom use IUDs) and 14.8 percent for traditional methods ${ }^{1}$. The prevailing pattern of using family planning methods shows that women use family planning methods only after the desired number of children, particularly male children, has been achieved. The almost universal knowledge of family planning methods suggests that lack of knowledge is not indicated as a barrier to contraceptive use in the Palestinian context. The PCBS Health Survey (1997) found the following to be the most common reported reasons for not using a family planning method: personal opposition, opposition from the family (husband or relatives), religious reasons and fear of side effects ${ }^{3}$. This finding points to the importance of involving family members (especially males) in family planning counseling services, as well as the importance of improving the quality of counseling by health care providers for all clients.

Breast cancer is the most prevalent type of cancer among Palestinian women. One study has reported that 28.5 percent of female cancers were due to breast cancer ${ }^{4}$, with the Ministry of Health $(\mathrm{MOH})$ reporting that 30 percent of female cancers were due to breast cancer according to its 2000 annual report ${ }^{5}$. The disease is usually diagnosed at an advanced stage, which leads to a poor prognosis ${ }^{6}$. The prevalence of cervical cancer appears to be low, although population-based data is lacking ${ }^{7}$. Pap smear testing is not systematically integrated in reproductive health programs in Palestine, and awareness-raising with regard to both breast-self examination and Pap smears has been repeatedly called for among both providers and women. 
The Pilot Health Project (PHP) was designed to address Palestinian women's most pressing reproductive health needs as described above. The PHP was designed and funded by the United States Agency for International Development (USAID) in collaboration with the Palestinian $\mathrm{MOH}$ and seven partners ${ }^{8}$, with the goal of improving the health status of Palestinian women and their children by upgrading antenatal and postnatal services in the West Bank and Gaza Strip. The intervention comprises a basic package of antenatal and postnatal services that target improving the health-seeking behaviors of clients and enhancing providers' technical knowledge and clinical practices.

\section{The PHP Basic Model of Services}

The PHP basic package of services (basic service delivery model) included the following components:

a. Improved maternal antenatal care in participating non-governmental organization (NGO) clinics.

b. A single home visit by the NGO community health worker (CHW) two to three days after delivery to assess the health condition of both the mother and the newborn, and to provide health education about breastfeeding and nutrition, care of the newborn, and immunization.

c. Counseling the mother on birth spacing and the need for postpartum contraception.

d. Encouraging the parents to bring the 10-day old

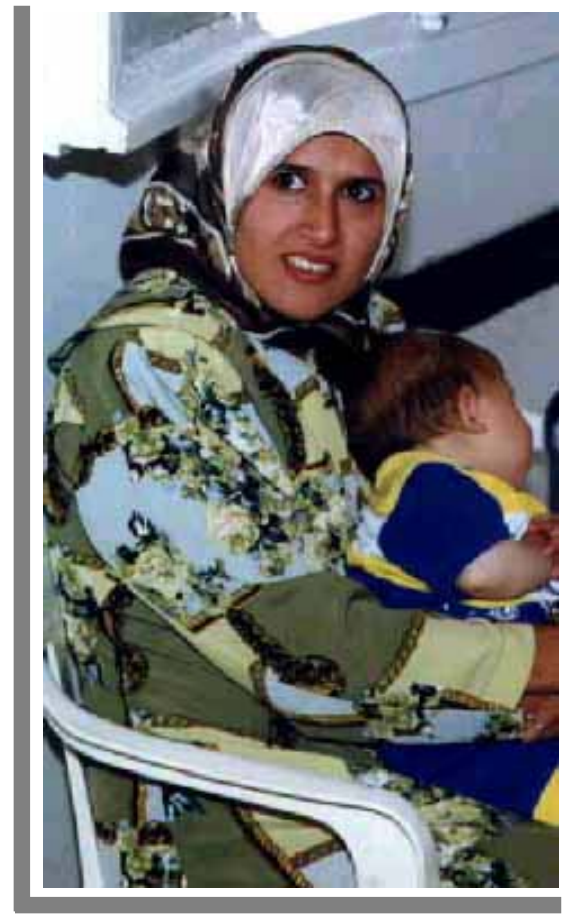
infant to the NGO clinic for a check-up by the doctor. Both clinic-based providers and CHWs will encourage the mother to return to the clinic with the newborn on day 40 after delivery for postpartum assessment of the baby and herself, including counseling about the health benefits of optimal birth spacing. During the day 40 visit, the mother will be urged to return again with the baby one month later for another check-up and for family planning follow-up and services.

\section{The Pre-test Survey}

A single cross-sectional study was conducted by the Health, Development, Information and Policy Institute (HDIP) between May and August 2000 in order to determine the baseline measures for the PHP's key outcome indicators among health care providers and clients in the PHP clinics. Information was collected on providers' technical knowledge and reported clinical practices as well as clients' knowledge and practices related to antenatal care, postpartum visits, care of the newborn, family planning, self-breast examinations and Pap smear tests. A complete report of the baseline survey is available from HDIP and the Population Council. 


\section{Study Objectives and Indicators}

The objective of the post-test survey was to evaluate the impact of the interventions introduced by the PHP by comparing changes between the pre-test and post-test survey on the following key outcome indicators (as identified in the original PHP design document):

1. Percentage of mothers and babies who return to the clinics to receive postpartum care out of those who received antenatal care (according to "mothers only," "mothers and babies together," and "babies only").

2. Percentage of mothers who accept a family planning method out of those who made return visits to the clinic.

3. Percentage of low parity women (one to two living children) accepting a family planning method.

4. Mothers' knowledge of antenatal and postpartum warning signs for themselves and their babies.

5. Percentage of women seeking treatment in case of recognizing a warning sign for themselves and their babies.

6. Women's knowledge and practice of self-breast examination and Pap smear tests.

7. Percentage of husbands and other males who are aware of the importance of at least a 36month birth interval, prenatal and postpartum care, and family planning use.

8. Knowledge and skills of all categories of health care providers.

9. Follow-up information given to women on antenatal and postpartum care, including nutrition, hygiene, breastfeeding and the need to use a family planning method. 


\section{METHODS}

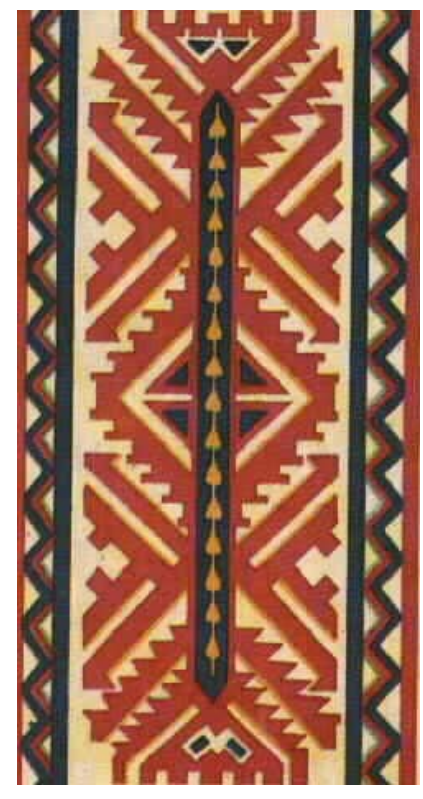

\section{Study Design}

The post-test survey utilized the same cross-sectional study design and data collection methods that the pre-test survey employed, namely:

- Standardized exit interviews with antenatal, postpartum and family planning clients.

$\bullet$

- Standardized interviews with health care providers (physicians, nurses, and CHWs).

It was not possible for the post-test survey to abstract information on caseloads from the NGOs' clinic records (as was done in the pre-test) because of the political unrest and related closures during data collection activities. The post-test survey utilized the same questions in its data collection instruments that were used in the pre-test and included some new items to collect additional information.

\section{Sampling Methods}

The same clinics were included in both the pre-test and post-test surveys. They are administered by the Union of Palestinian Medical Relief Committees (UPMRC), the Union of Health Work Committees (UHWC) and the Patients Friends Society (PFS) and are located in Jenin, the northern area of the West Bank; Hebron, the southern area of the West Bank; and in the Gaza Strip. The post-test survey excluded one of the 27 clinics that was included in the pre-test survey (Al-Awda hospital clinic in Gaza), because it had ceased to provide women's health services (Table 1), and was hence no longer a participating PHP site. The elimination of this site is not expected to introduce any bias to the study findings.

Of the 26 remaining clinics included in the post-test survey, 20 are located in the Jenin district, two in the Hebron district, and four in the Gaza Strip. All of the PHP clinics administered by Palestinian Friends Society are located in the Jenin district, while the two clinics surveyed in Hebron are administered by the Union of Palestinian Medical Relief Committees. The clinics in Gaza are all administered by the Union of Health Work Committees. 
Table 1: Location, Affiliation and Staffing of the PHP Project Clinics in the Posttest Survey

\begin{tabular}{|c|c|c|c|c|c|c|}
\hline \multirow[t]{2}{*}{ Village and Clinics } & \multirow[t]{2}{*}{ District } & \multirow[t]{2}{*}{ NGO } & \multicolumn{2}{|c|}{ Physicians } & \multicolumn{2}{|c|}{$\begin{array}{c}\text { Nurses and } \\
\text { Community } \\
\text { Health Workers }\end{array}$} \\
\hline & & & Pre & Post & Pre & Post \\
\hline Qabatia & Jenin & PFS & & & 1 & 1 \\
\hline Dier Abu D'ief & Jenin & PFS & & & 1 & 1 \\
\hline Rumaneh & Jenin & PFS & & 1 & 1 & 1 \\
\hline Kurfdan & Jenin & PFS & & 1 & 1 & 1 \\
\hline Al-Almanieh & Jenin & PFS & & & 1 & 1 \\
\hline Misielieh & Jenin & PFS & & & 1 & 1 \\
\hline Araneh & Jenin & PFS & 1 & & & 1 \\
\hline Zabdeh & Jenin & PFS & & & & 1 \\
\hline $\begin{array}{l}\text { Nazlet Al Shiekh } \\
\text { Hussain }\end{array}$ & Jenin & PFS & & & 1 & 1 \\
\hline Al-Tarem & Jenin & PFS & & & & 1 \\
\hline Al-Fundoukomieh & Jenin & PFS & 1 & & 2 & 1 \\
\hline Mashro' Beit-Qad & Jenin & PFS & & & 1 & 1 \\
\hline Ta'anak & Jenin & PFS & & & 2 & 1 \\
\hline Sier & Jenin & PFS & & & & 1 \\
\hline Al-Shuhada & Jenin & PFS & & & 1 & 1 \\
\hline Sielet Alharthieh & Jenin & UPMRC & & & 2 & 3 \\
\hline Miethaloon & Jenin & UPMRC & 1 & 1 & 3 & 3 \\
\hline Al-Zababdeh & Jenin & UPMRC & 1 & & 1 & 2 \\
\hline Toubas & Jenin & UPMRC & & 1 & 2 & 2 \\
\hline Al-Nassarieh & Jenin & UPMRC & & & 2 & 2 \\
\hline Sub-total & Jenin & & 4 & 4 & 23 & 27 \\
\hline Ithna & Hebron & UPMRC & & 1 & 5 & 4 \\
\hline Ras El Joura & Hebron & UPMRC & 1 & & 2 & 2 \\
\hline Sub-total & Hebron & & 1 & 1 & 7 & 6 \\
\hline $\begin{array}{l}\text { Biet-Hanoun/Alquds } \\
\text { Clinic }\end{array}$ & Gaza & UHWC & 1 & 1 & 6 & 4 \\
\hline Jabalia Camp & Gaza & UHWC & 2 & 1 & 5 & 4 \\
\hline $\begin{array}{l}\text { Al-Nusseirat Camp/ } \\
\text { Alkhirieh Clinic }\end{array}$ & Gaza & UHWC & & 1 & & 4 \\
\hline Rafah Medical Center & Gaza & UHWC & 1 & 1 & & 4 \\
\hline Al-Awda Hospital & Gaza & UHWC & & & 4 & \\
\hline Sub-total & Gaza & & 4 & 4 & 15 & 16 \\
\hline Total & & & 9 & 9 & 45 & 49 \\
\hline
\end{tabular}




\section{Sample Size and Eligibility}

All consenting antenatal, postpartum, and family planning clients who visited the PHP clinics during the data collection period were eligible for exit interviews (see the section on field data collection for more details). The sample for the post-test survey originally planned to interview 1,000 women (43 interviews per clinic). The actual sample achieved was 1,070 (Table 2). The distribution of the clients interviewed in the post-test was very close to that of the pre-test survey (see Box 1) (65.2\% from Jenin, 13.7\% from Hebron, and 21.0\% from Gaza). Clients who came to the clinic for gynecological or any other primary health care consultations were not eligible for participation in either survey. In addition, all consenting service providers were interviewed who worked at PHP clinics at the time of both surveys (not all of the health providers were the same in both surveys). A total of nine physicians and 49 nurses and CHW interviews were completed in the post-test survey to assess the change in technical knowledge and clinical skills of those service providers following the launching of the PHP interventions.

\begin{tabular}{|c|c|c|c|c|c|c|}
\hline \multicolumn{7}{|c|}{$\begin{array}{l}\text { Box 1: Clients and service providers interviewed in the pre-test } \\
\text { and post-test surveys by PHP areas }\end{array}$} \\
\hline \multirow{2}{*}{ PHP areas } & \multirow[b]{2}{*}{ Pre } & \multirow[b]{2}{*}{ Post } & \multicolumn{2}{|c|}{ Physicians } & \multicolumn{2}{|c|}{ Nurses and CHWs } \\
\hline & & & Pre & Post & Pre & Post \\
\hline Jenin & 515 & 698 & 4 & 4 & 23 & 27 \\
\hline Hebron & 101 & 147 & 1 & 1 & 7 & 6 \\
\hline Gaza & 176 & 225 & 4 & 4 & 15 & 16 \\
\hline Total & 792 & 1070 & 9 & 9 & 45 & 49 \\
\hline \multicolumn{7}{|c|}{ Source: Tables 1 and 2} \\
\hline
\end{tabular}

\section{Data Collection Procedures}

\section{Obstacles Encountered During Data Collectors' Training and Field Data Collection Phases}

There were two main difficulties that impeded the planning and implementation of the data collectors' training and data collection activities: the political situation and the irregular work schedules of providers.

\section{The political situation}

The post-test survey took place under an extraordinarily difficult security situation associated with the Al-Aqsa Intifada, which commenced in September 2000. Widespread checkpoints and the complete closure of some Palestinian cities and villages caused delays in fieldwork and necessitated changes in the training and data collection plans. Below are some examples.

- Separate training sessions by separate trainers had to be conducted in the West Bank and the Gaza Strip because of the extreme difficulty in accessing Gaza.

- Field data collectors' training for the West Bank was conducted centrally in Ramallah over only one day. This was necessary to avoid difficulties that might be faced by those persons trying to get back to their home villages. 
Table 2: Sample Distribution Results by Clinic and Reasons for Visiting the Clinic

\begin{tabular}{|l|c|c|c|c|c|c|c|c|c|}
\hline \multirow{2}{*}{ Study Site } & \multicolumn{7}{|c|}{ Pre-test Survey } & \multicolumn{3}{c|}{ Post-test Survey } \\
\cline { 2 - 10 } & ANC & PP & FP & $\begin{array}{c}\text { PP } \\
\mathbf{8}\end{array}$ & $\begin{array}{c}\text { Tot } \\
\text { al }\end{array}$ & $\begin{array}{c}\text { AN } \\
\text { C }\end{array}$ & PP & FP & Total \\
\hline JENIN & & & & FP & & & & \\
Qabatia & 27 & 1 & 6 & 1 & 35 & 50 & 5 & 34 & 89 \\
Dier Abu D'ief & 30 & & 5 & & 35 & 24 & & 13 & 37 \\
Rumaneh & 28 & & 5 & & 33 & 28 & 2 & 8 & 38 \\
Kurfdan & 34 & 1 & 8 & 3 & 46 & 27 & 1 & 31 & 59 \\
Al-Almanieh & 11 & & 1 & & 12 & 5 & 1 & 4 & 10 \\
Misielieh & 14 & 1 & 3 & & 18 & 20 & 1 & 25 & 46 \\
Araneh & 9 & & 3 & & 12 & 9 & 4 & 13 & 26 \\
Zabdeh & 9 & & & & 9 & 6 & & 5 & 11 \\
Nazlet Al Shiekh Hussain & 6 & & & & 6 & 11 & 1 & 7 & 19 \\
Al-Tarem & 2 & & 1 & & 3 & 6 & & 8 & 14 \\
Al-Fundoukomieh & 34 & 1 & 7 & 1 & 43 & 19 & 1 & 13 & 33 \\
Mashro' Beit-Qad & 6 & & & & 6 & 6 & 2 & 2 & 10 \\
Ta'anak & 7 & 1 & 1 & & 9 & 11 & & 4 & 15 \\
Sier & 1 & & & & 1 & 6 & 2 & 9 & 17 \\
Al-Shuhada & 6 & & 1 & & 7 & 8 & 1 & 3 & 12 \\
Sielet Alharthieh & 49 & 1 & 2 & 1 & 53 & 32 & 4 & 20 & 56 \\
Miethaloon & 65 & 2 & 11 & 2 & 84 & 100 & 4 & 45 & 149 \\
Al-Zababdeh & 34 & & 3 & 1 & 40 & 20 & 1 & 13 & 34 \\
Toubas & 30 & 1 & 14 & 1 & 48 & 13 & & 4 & 17 \\
Al-Nassarieh & 15 & 1 & 7 & & 23 & 4 & & 2 & 6 \\
Sub-total & $\mathbf{4 1 7}$ & $\mathbf{1 0}$ & $\mathbf{7 8}$ & $\mathbf{1 0}$ & $\mathbf{5 1 5}$ & $\mathbf{4 0 5}$ & $\mathbf{3 0}$ & $\mathbf{2 6 3}$ & $\mathbf{6 9 8}$ \\
\hline HEBRON & & & & & & & & & \\
Ithna & 63 & & 2 & & 65 & 46 & 7 & 61 & 114 \\
Hebron & 28 & 1 & 7 & & 36 & 20 & 3 & 10 & 33 \\
Sub-total & $\mathbf{9 1}$ & $\mathbf{1}$ & $\mathbf{9}$ & & $\mathbf{1 0 1}$ & $\mathbf{6 6}$ & $\mathbf{1 0}$ & $\mathbf{7 1}$ & $\mathbf{1 4 7}$ \\
\hline GAZA & & & & & & & & & \\
Biet Hanoun/Alquds Clinic & 70 & 2 & 7 & & 79 & 33 & 2 & 11 & 46 \\
Jabalia Camp & 34 & 1 & 8 & & 43 & 54 & & 4 & 58 \\
Al-Nusseirat Camp/Alkhirieh Clinic & & & 2 & & 2 & 52 & & 3 & 55 \\
Rafah Medical Center & 1 & 1 & 1 & & 3 & 60 & 3 & 3 & 66 \\
Al-Awda Hospital & 43 & 2 & 4 & & 49 & & & & \\
Sub-total & $\mathbf{1 4 8}$ & $\mathbf{6}$ & $\mathbf{2 2}$ & & $\mathbf{1 7 6}$ & $\mathbf{1 9 9}$ & $\mathbf{5}$ & $\mathbf{2 1}$ & $\mathbf{2 2 5}$ \\
\hline Total & $\mathbf{6 5 6}$ & $\mathbf{1 7}$ & $\mathbf{1 0 9}$ & $\mathbf{1 0}$ & $\mathbf{7 9 2}$ & $\mathbf{6 7 0}$ & $\mathbf{4 5}$ & $\mathbf{3 5 5}$ & $\mathbf{1 0 7 0}$ \\
\hline
\end{tabular}

- There were delays and difficulties in sending the study instruments to the data collectors in the field, as well as sending them from the data collectors to supervisors (for review and checking).

- Travel distances were increased because of the closures, which meant that field data collectors spent more time traveling to and from distant clinics, leaving less available time for filling out the study instruments, which resulted in a slower pace of work.

- The political unrest and the difficult conditions on the roads discouraged some women from visiting the clinics. 


\section{Irregular work schedules of providers}

The irregular work schedules of providers, especially in small clinics in distant villages, meant that data collection activities often could not proceed as planned. Physicians, nurses, and CHWs were sometimes not able to attend clinics on their appointed days, or were delayed because of the security situation. This resulted in data collectors having very low caseloads to work with (if the physician was only at the clinic for an hour) or having to re-schedule their visits altogether. Given that physicians work on a rotating schedule in most of the clinics (which means that in most clinics, doctors are only present once or twice a week and even less frequently for maternal and child health services), and that clients could only be interviewed following a physician's visit, there were limited days on which data collection could proceed.

\section{Data Collectors’ Training}

It was not possible for the post-test survey to recruit the same data collectors who were engaged in the field operations during the pre-test survey. Most of them were busy with other jobs, and it was not possible to recruit those who were available because of closures. Instead, local data collectors were employed.

Separate training sessions were held for fieldworkers in the West Bank and Gaza Strip. The West Bank training took place in Ramallah on October 21, 2001 for the client instrument and October 22, 2001 for the instruments of the health care providers. Due to the political unrest and problems with roadblocks and transportation, training had to be abbreviated to one day for each instrument. Eleven field workers were trained on the use of the client instrument in the West Bank by the same trainer employed in the pre-test survey. Field workers received training on the concepts used for the study objectives as well as detailed training on the questions included in the instrument. Further, training included discussion about determining eligibility, informed consent and dealing with clients who refuse to be interviewed. Twelve field workers were trained by a second trainer on the use of the providers' instrument.

Training in Gaza took place on October 29, 2001 and was conducted by a third trainer. Seven field workers were recruited for this

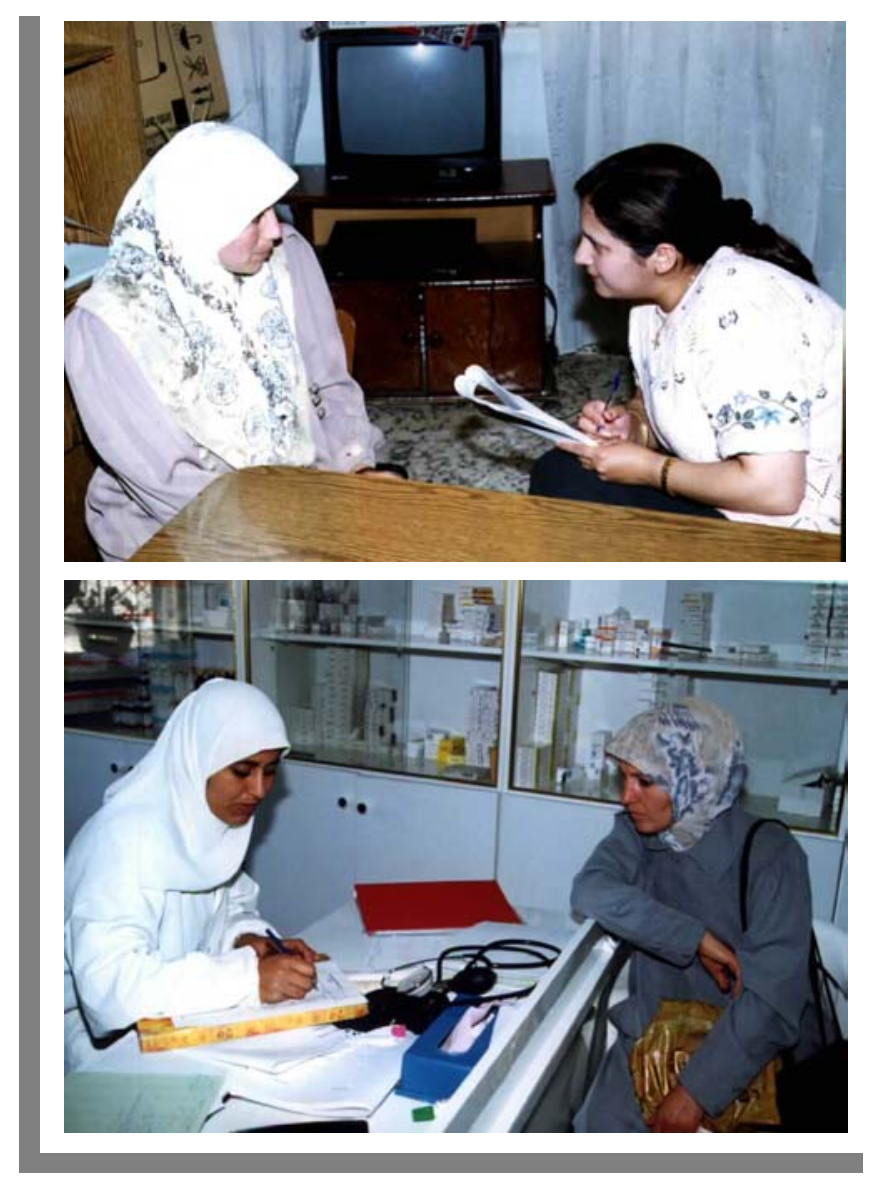


purpose, and they received the same training curriculum as the field workers from the West Bank.

Field Data Collection

Data collection in the

West Bank took place between October 28 and November 28, 2001 in the Jenin and Hebron areas. In the Gaza Strip, data collection was carried out between October 30 and December 8, 2001. The supervisors in each area interviewed physicians, nurses, and CHWs.

Data Processing and Analysis

Data processing took place at Alpha International's Office in Ramallah. Working sessions were held with key HDIP staff who were involved in developing the pre-test data set in order to develop the merged clean tape (pre-test / post-test). This was followed by data analysis that was conducted by senior staff of Alpha International in collaboration with the Population Council's Cairo-based staff.
Table 3: Selected Demographic and Socio-economic Characteristics of Women and their Husbands in the Pre-test and Post-test

\begin{tabular}{|c|c|c|}
\hline Women's characteristics & Pre (\%) & Post (\%) \\
\hline Age & $(n=792)$ & $(n=1070)$ \\
\hline $15-19$ & 12.5 & 9.7 \\
\hline $20-24$ & 30.7 & 31.2 \\
\hline $25-29$ & 25.8 & 27.6 \\
\hline $30-34$ & 17.6 & 16.4 \\
\hline $35-39$ & 10.9 & 10.3 \\
\hline $40-44$ & 2.3 & 3.7 \\
\hline $45+$ & 0.4 & 1.1 \\
\hline Mean age & 26.5 & $27.1 *$ \\
\hline \multicolumn{3}{|l|}{ Occupation } \\
\hline Housewife & 96.1 & 93.5 \\
\hline Working & 3.3 & 5.2 \\
\hline Student & 0.6 & 1.3 \\
\hline \multicolumn{3}{|l|}{ Education } \\
\hline None & 11.2 & 7.7 \\
\hline Primary (6 years) & 27.0 & 24.3 \\
\hline Preparatory (9 years) & 35.5 & 40.7 \\
\hline Secondary (High School / 12 years) & 17.2 & 16.0 \\
\hline Technical ( $<4$ years after high school) & 6.8 & 7.7 \\
\hline University (4 years after high school) & 2.0 & 2.7 \\
\hline Post-graduate ( $>4$ years after high school) & 0.3 & 0.8 \\
\hline Mean schooling years completed & 9.2 & $9.6^{* *}$ \\
\hline \multicolumn{3}{|l|}{ Husbands' characteristics } \\
\hline Age & & \\
\hline$<25$ & 13.8 & 8.7 \\
\hline $25-34$ & 55.7 & 55.9 \\
\hline $35+$ & 30.6 & 35.4 \\
\hline Mean age & 31.7 & 32.7 \\
\hline $\begin{array}{l}\text { Mean age difference between husband and } \\
\text { wife/ years }\end{array}$ & 5.3 & $5.9^{* *}$ \\
\hline \multicolumn{3}{|l|}{ Husband's occupation } \\
\hline Unemployed & 2.3 & 5.3 \\
\hline Unskilled laborer & 39.0 & 40.8 \\
\hline Skilled laborer & 21.1 & 17.7 \\
\hline Agriculture & 4.4 & 6.3 \\
\hline Employee & 22.1 & 22.1 \\
\hline Business owner & 10.9 & 7.8 \\
\hline \multicolumn{3}{|l|}{ Education } \\
\hline$<10$ years & 37.0 & 35.3 \\
\hline $10+$ & 63.0 & 64.7 \\
\hline Mean schooling years completed & 11.0 & 10.8 \\
\hline \multicolumn{3}{|l|}{ Husband's relationship to wife } \\
\hline Related to wife & 50.8 & 49.7 \\
\hline \multicolumn{3}{|l|}{ Kind of relationship } \\
\hline First cousin & 53.0 & 56.0 \\
\hline Second or higher order cousin & 39.6 & 38.2 \\
\hline From hamoula & 6.2 & 5.3 \\
\hline Others & 1.2 & 0.6 \\
\hline Husband has other wives (\% yes) & 2.3 & 3.8 \\
\hline
\end{tabular}

$* \mathrm{P}<0.05$

$* * \mathrm{P}<0.01$

Source: client exit interview 


\section{FINDINGS}

\section{Selected Background Characteristics of Clients and Their Husbands}

Table 3 presents selected socio-economic and demographic characteristics of the women who were interviewed, as well as information provided by the women about their husbands (who were not interviewed). The average age of women participating in the post-test survey was 27.1 years, while their husbands' average age was 32.7 years. Women in the post-test survey were slightly older than in the pre-test survey. The age difference (approximately 0.6 years), though statistically significant, is not meaningful. Women aged 20-29 years constituted approximately three-fifths of the women surveyed. On average, women in the post-test had completed 9.6 years of schooling. Similar to the difference in mean age between the pre- and post-test surveys, there is a small yet statistically significant difference in the mean number of schooling years, which is of little substantive value. About 8 percent reported having no education at all, and little more than 3 percent of women have attained a university degree (indicating post graduate). About 94 percent of women were housewives, and only about 5 percent reported working outside the home. On average, husbands were better educated than their wives, with mean schooling years of 10.8 versus 9.6 for wives. They were reportedly mostly unskilled laborers (about $41 \%$ ), whitecollar employees (about 22\%), and skilled laborers (about 18\%), while about 5 percent were reportedly unemployed at the time of the survey. Approximately one-half of the women surveyed were related to their husbands, and of that half, 56 percent were married to a first cousin, and over one-third were married to a second or higher order cousin. Of all the women surveyed, approximately 28 percent were married to a first cousin, a proportion similar to the national estimate ${ }^{9}$. The above socio-economic and demographic indicators are very close to the indicators reflected by the pre-test survey.

\section{Profile of Women's Living Conditions}

In general, the living conditions of women in the pre- and post-test surveys were very similar. Women in the post-test survey came from households with an average size of 6.3 persons, and an average crowding ratio (persons per room) of 2.0 (Table 4). Approximately three-quarters of the women lived in nuclear families (husband and children only), which was comparable to the pretest survey. Those who lived in extended family settings were most likely to be living with the mother-in-law (about 76\%), the husband's brothers or sisters (68\%), and the father-in-law (about $48 \%)$. Nearly all households had a color television $(90.9 \%)$ and the majority had a refrigerator (87.5\%). Piped water was almost universal (about 95\%). It should be noted here that the large increase in availability of piped water in the post-test survey compared to the pre-test survey $(65.3 \%)$ was due to a donor-funded water project. Telephones/mobile phones and manual 
Table 4: Profile of Women's Living Conditions

\begin{tabular}{|l|c|c|}
\hline \multicolumn{2}{|c|}{ Pre } & Post \\
\hline Characteristic & $\mathbf{( n = 7 9 2 )}$ & $\mathbf{( n = 1 0 7 0 )}$ \\
Average household size/persons per household & 6.8 & $6.3^{* *}$ \\
Average number of rooms & 3.9 & $3.4^{* *}$ \\
Crowdedness (persons/room) & 2.0 & 2.0 \\
\hline People living in household & \multicolumn{2}{|c|}{} \\
\hline Characteristics & $\mathbf{( \% )}$ & $\mathbf{( \% )}$ \\
Husband and children only & 67.7 & 74.0 \\
Somebody else living with the family & $\mathbf{( n = 2 5 6 )}$ & $\mathbf{( n = 2 7 8 )}$ \\
Mother-in-law & 86.3 & 76.3 \\
Father-in-law & 58.6 & 47.8 \\
Husband's brothers or sisters & 67.2 & 68.0 \\
Wife's mother & 1.6 & 1.8 \\
\hline Household that own & 23.2 & 22.1 \\
Private car & 90.9 & 90.9 \\
Color TV & 86.9 & 87.5 \\
Refrigerator & 64.8 & $60.2^{*}$ \\
Manual washing machine & 12.1 & 10.9 \\
Fully automatic washing machine & 15.0 & $18.8^{*}$ \\
Semi-automatic washing machine & 15.3 & 13.6 \\
Video & 29.2 & $35.2^{* *}$ \\
Satellite dish & 64.0 & $74.3^{* *}$ \\
Telephone or mobile phone & 65.3 & $94.6^{* *}$ \\
Household with piped water & & \\
\hline Socio-economic Status (SES) indicator & \\
Low (0-4) & 45.8 & 41.6 \\
Medium (5-6) & 48.5 & 52.4 \\
High (7-8) & 5.7 & 6.0 \\
Mean SES & 4.5 & 4.6 \\
*P<0.05 & &
\end{tabular}

$* \mathrm{P}<0.05$

$* * \mathrm{P}<0.01$

Source: client exit interview

${ }^{1} \mathrm{~A}$ composite indicator for socio-economic status of the household. It includes 8 variables with the value one for possession or zero for no possession: (1) private care, (2) color TV, (3) refrigerator, (4) manual washing machine, (5) satellite dish, (6) telephone or mobile phone, (7) a semi-automatic washing machine. The eighth variable is an indicator of crowdedness (number of persons per room): if less than or equal $2=1$, if 2 or more=zero. The composite SES indicator has a value ranging between 0 and 8 .

washing machines were also very common. Only about 11 percent of households owned a fully automatic washing machine, about 19 percent owned a semi-automatic washing machine and about one-fifth had a private car. The proportion of households with a satellite dish or mobile phone had increased somewhat by the time of the post-test survey. Based on the number of household amenities owned, a composite index of the socio-economic status (SES) of women's households was constructed with a scale ranging from zero to eight for assessing SES, (the score composition is explained at the bottom of Table 4). The mean socio-economic status score was 4.6, reflecting a medium SES level, which is comparable to the pre-test score of 4.5 . 


\section{Women's \\ Reproductive Health Profile}

The mean age at first marriage is 18.8 years in the post-test survey, while the mean age at first pregnancy is 19.3 years (Table 5). Both figures are close to the national average ${ }^{10}$ and are comparable to the pre-test sample. The mean number of children ever born alive to women in the post-test survey is 3.6 Table 5: Women's Reproductive Health History Profile

\begin{tabular}{|l|c|c|}
\hline Characteristic & Pre & Post \\
\cline { 2 - 3 } Mean age at first marriage & $18.5(\mathrm{n}=792)$ & $18.8(\mathrm{n}=1066)$ \\
Mean age at first pregnancy & $19.1(\mathrm{n}=662)$ & $19.3(\mathrm{n}=952)$ \\
Mean number of children ever born alive & $3.0(\mathrm{n}=772)$ & $3.6(\mathrm{n}=948)$ \\
Mean number of children born alive then died & $0.1(\mathrm{n}=772)$ & $0.2(\mathrm{n}=949)$ \\
\hline Living Children & & \\
0 & 16.5 & 2.6 \\
$1-2$ & 33.0 & 36.9 \\
$3-4$ & 23.5 & 34.5 \\
$5+$ & 27.0 & 26.0 \\
\hline Mean age of youngest child (years) & $2.4(\mathrm{n}=642)$ & $2.4(\mathrm{n}=934)$ \\
\hline Mean number of living children & $2.9(\mathrm{n}=772)$ & $3.6(\mathrm{n}=951)$ \\
Boys & 1.4 & 1.8 \\
Girls & 1.5 & 1.8 \\
\hline Women aged 40+ years & Pre $(\mathrm{n}=21)$ & $\operatorname{Post}(\mathrm{n}=52)$ \\
Mean number of children ever born alive & 7.2 & 7.9 \\
Mean number of living children & 6.9 & 7.5 \\
\hline Mean number of previous stillbirths & $0.044(\mathrm{n}=792)$ & $0.074(\mathrm{n}=1070)$ \\
Mean number of previous miscarriages & $0.62(\mathrm{n}=792)$ & $0.57(\mathrm{n}=1070)$ \\
\hline
\end{tabular}

Source: client exit interview compared to 3.0 in the pre-test survey, which is not statistically significant. The mean number of living children was also higher for women in the post-test compared to the pre-test survey (3.6 and 2.9, respectively) but again, this difference is not statistically significant. For women in the post-test survey who were 40 years old and over (women approaching the end of their reproductive years), the mean number of children ever born alive was 7.9, and the mean number of living children was 7.5. The incidence of stillbirths and miscarriages reported in both the pretest and the post-test is low.

\section{Fertility Preferences}

In both pre-test and post-test surveys women were asked about their own and their husbands' fertility preferences (the desire for more children and gender preference). These results are presented in Table 6. In general, these findings reflected higher fertility preferences among husbands compared to wives, and a decline in the proportion of both wives and husbands who want more children over the period of the PHP, (a statistically PHP, (a statistically significant decline for most indicators). There was a drop of seven percentage points among women and 16 percentage points among husbands who wanted more children. As expected, the
Table 6: Desire for Additional Children by Number of Living Children and Living Sons

\begin{tabular}{|c|c|c|c|c|}
\hline & \multicolumn{2}{|c|}{$\begin{array}{c}\text { Percent of women } \\
\text { who want more } \\
\text { children }\end{array}$} & \multicolumn{2}{|c|}{$\begin{array}{c}\text { Percent of husbands } \\
\text { who want more } \\
\text { children }\end{array}$} \\
\hline & Pre & Post & Pre & Post \\
\hline $\begin{array}{l}\text { All women / } \\
\text { husbands }\end{array}$ & $\begin{array}{c}52.7 \\
(n=658)\end{array}$ & $\begin{array}{c}46.4 \\
(n=901)\end{array}$ & $\begin{array}{c}73.7 \\
(n=680)\end{array}$ & $\begin{array}{c}58.2 * \\
(n=920)\end{array}$ \\
\hline \multicolumn{5}{|c|}{ Number of living children } \\
\hline 0 & 75.6 & 92.0 & 85.5 & 88.5 \\
\hline $1-2$ & 59.5 & 56.6 & 79.9 & $62.5^{*}$ \\
\hline $3-4$ & 42.2 & 38.5 & 66.9 & $55.0 * *$ \\
\hline $5+$ & 30.1 & 30.7 & 59.1 & 50.0 \\
\hline \multicolumn{5}{|c|}{ Number of living sons } \\
\hline 0 & 71.1 & 66.4 & 83.4 & $70.4^{*}$ \\
\hline 1 & 52.2 & 47.2 & 73.3 & $59.7 *$ \\
\hline 2 & 40.7 & 42.2 & 70.9 & $54.8 *$ \\
\hline 3 & 24.0 & 25.5 & 57.4 & 43.8 \\
\hline $4+$ & 25.4 & 31.3 & 55.0 & 51.2 \\
\hline
\end{tabular}


proportion of women expressing a desire for more children decreased with the increase in number of living children. Similarly, the desire for more children decreased with the increase in number of living sons. Women's desire to have more children dropped sharply after having two living sons. Similar patterns were noted for husbands.

With regard to the sex preference for the next child among those who reported wanting more children, the data clearly indicate a preference for males among both husbands and wives, with stronger male preference among husbands (Table 7). The overall preference for the next child to be a boy remained almost the same in the two surveys among both husbands and wives.

\section{Selected Background}

\section{Characteristics of Nurses and CHWs}

A total of 49 providers were interviewed in the post-test survey, 13 nurses and 36 community health workers (CHWs) (Table 8). Their mean age was 33.3 years, and 59.2 percent of them had a diploma, but only a few of them attained a B.A. degree (about 4\%). On average, the nurses and CHWs had been working at the clinics in which they were interviewed for about five years. Compared to their counterparts in the pretest survey, the nurses and CHWs in the post-test survey were slightly younger and better educated.
Table 7: Sex Preference for Next Child

\begin{tabular}{|c|c|c|c|c|c|c|}
\hline \multicolumn{7}{|c|}{ Among women who want more children } \\
\hline & \multicolumn{2}{|c|}{ Boy } & \multicolumn{2}{|c|}{ Girl } & \multicolumn{2}{|c|}{ Up to God } \\
\hline & Pre & Post & Pre & Post & Pre & Post \\
\hline Total* & 27.5 & 31.7 & 10.6 & 15.9 & 61.9 & 52.4 \\
\hline \multicolumn{7}{|c|}{ Sex composition of living children } \\
\hline No boys* & 35.8 & 59.2 & 6.7 & 1.7 & 57.5 & 39.2 \\
\hline No girls* & 16.3 & 15.3 & 20.5 & 37.8 & 63.2 & 46.8 \\
\hline Boys $>$ Girls* & 7.0 & 14.1 & 26.1 & 37.8 & 67.0 & 48.1 \\
\hline Boys $=$ Girls & 21.3 & 20.5 & 8.3 & 1.2 & 70.1 & 78.3 \\
\hline Boys $<$ Girls & 49.7 & 59.0 & 0.7 & 2.8 & 49.7 & 38.2 \\
\hline \multicolumn{7}{|c|}{ Among husbands who want more children ${ }^{1}$} \\
\hline & \multicolumn{2}{|c|}{ Boy } & \multicolumn{2}{|c|}{ Girl } & \multicolumn{2}{|c|}{ Up to God } \\
\hline & Pre & Post & Pre & Post & Pre & Post \\
\hline Total & 36.0 & 37.4 & 7.0 & 9.5 & 57.0 & 53.1 \\
\hline \multicolumn{7}{|c|}{ Sex composition of living children } \\
\hline No boys* & 36.7 & 53.7 & 8.7 & 0.8 & 54.6 & 45.0 \\
\hline No girls & 23.0 & 26.5 & 14.7 & 21.2 & 62.3 & 52.2 \\
\hline Boys $>$ Girls** & 28.1 & 25.0 & 10.5 & 20.7 & 61.4 & 61.4 \\
\hline Boys $=$ Girls & 22.7 & 29.8 & 9.4 & 3.8 & 68.0 & 66.3 \\
\hline Boys $<$ Girls & 56.0 & 54.6 & 1.7 & 2.6 & 42.8 & 42.3 \\
\hline \multicolumn{7}{|c|}{$\begin{array}{l}{ }^{1} \text { As reported by wives } \\
* \mathrm{P}<0.01 \\
* * \mathrm{P}<0.05\end{array}$} \\
\hline
\end{tabular}

Table 8: Selected Background Characteristics of Nurses and CHWs in PHP Clinics

\begin{tabular}{|l|c|c|}
\hline Characteristic & $\begin{array}{c}\text { Pre (\%) } \\
(\mathbf{n = 4 5 )}\end{array}$ & $\begin{array}{c}\text { Post (\%) } \\
(\mathbf{n}=\mathbf{4 9})\end{array}$ \\
\hline Age & 17.8 & 32.7 \\
$<30$ years & 60.0 & 49.0 \\
30-39 years & 22.2 & 18.4 \\
40 years and above & 34.8 & 33.3 \\
Mean age & & \\
Education (highest degree attained) & 42.2 & 34.7 \\
None and Tawjihi & 57.8 & 59.2 \\
Diploma & - & 4.1 \\
BA or BSc & & \\
\hline Years working at the clinic (completed years) & 28.9 & 32.7 \\
0-2 & 40.0 & 22.4 \\
$3-5$ & 31.1 & 44.9 \\
6+ & 5.0 & 5.3 \\
Mean number of years working in the clinic & & \\
\hline Number of working days per week & 31.1 & 20.4 \\
3 & 2.2 & 6.1 \\
4 & - & 4.1 \\
5 & 66.7 & 67.3 \\
6 & - & 2.0 \\
\hline
\end{tabular}

Source: Nurse / CHW interview 
About two-thirds of the nurses and CHWs in both pre-test and post-test surveys work six days per week, while most of others work only three days a week.

\section{Selected Background Characteristics of Physicians}

A total of nine physicians were identified working at PHP clinics in both pre-test and post-test surveys and each of them were interviewed in both surveys. The findings indicate that the mean age of physicians in the posttest survey was 32.6 years, and all but one reported being a general practitioner/women's health specialist (see Table 9). On average, physicians have been working at their NGOs for 3.4 years and at the clinic in which they were interviewed for about two years. Some of those physicians, especially those affiliated with the Patient's Friends Society, rotate among a number of clinics in some villages to provide $\mathrm{MCH}$ and family planning services. Eight out of the nine physicians interviewed reported working at other health facilities, and seven out of the nine physicians in the post-test survey reported that they need training on certain aspects of women's health.

\section{Reasons for Visits}

Both pre-test and post-test surveys collected information from women on their reasons for visiting the clinic (Figure 1). As in the pre-test survey, antenatal care accounted for the largest proportion of visits (about 63\%) in the post-test survey. However, despite the very small number of postpartum visits, it is important to note the significant change between the pre-test and posttest surveys, where the proportion of postpartum visits doubled from 2.1 to 4.2 percent, respectively. Furthermore, the proportion of visits for family planning services increased almost two-and-a-half fold between the two surveys. 


\section{Figure 1: Reasons for Clinic Visit}

\section{Pre-test \%}

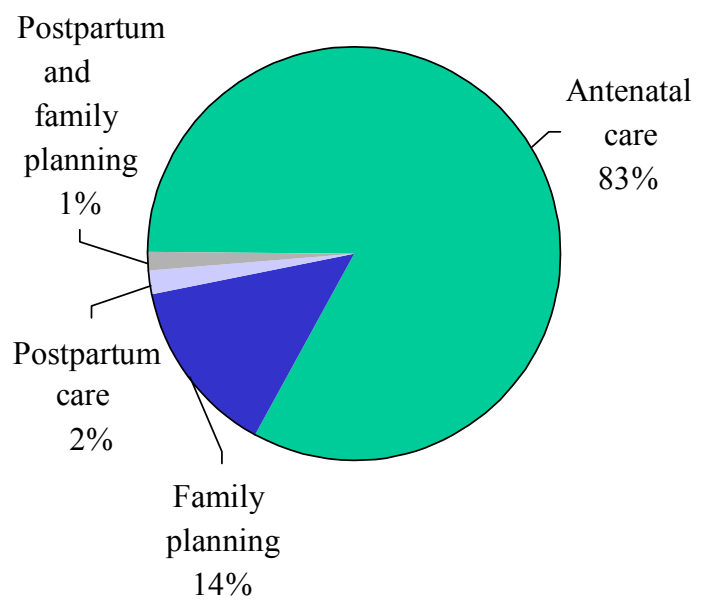

Post-test \%

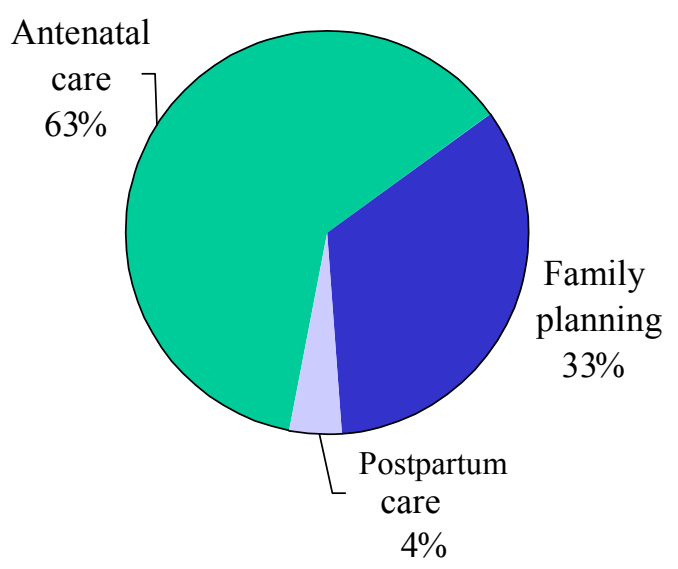

Source: client exit interviews

(pre $\mathrm{n}=792),($ post $\mathrm{n}=1070)$ 


\title{
POST-INTERVENTION LEVELS OF KEY OUTCOME INDICATORS FOR THE PHP
}

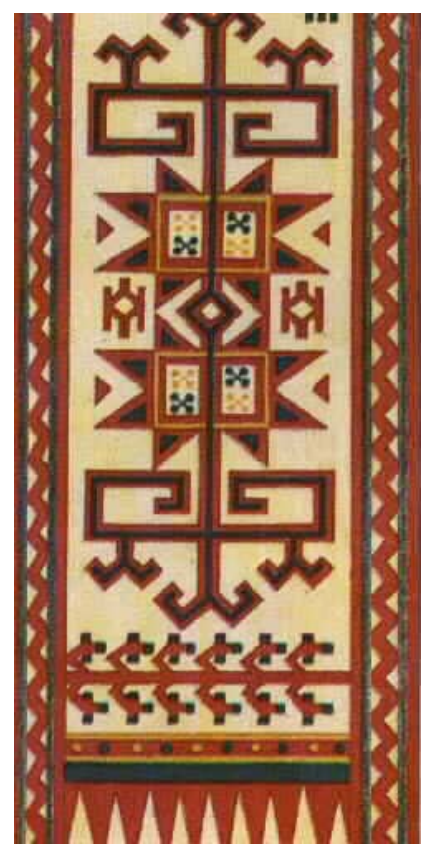

\author{
[E] Indicator 1: Percentage of mothers and babies who \\ return to the clinics to receive postpartum care, \\ among those who received antenatal care
}

Ideally, data on this indicator should have been obtained from the Management Information Systems (MIS) of the PHP service delivery NGOs (as noted in the pre-test report). However, the existing health information systems at the time of the pre-test were shown to have many gaps and weaknesses (as reflected by the assessment conducted by HDIP ${ }^{11}$ ). At the time of the post-test, the PHP's MIS was not yet at a stage where this type of data were being routinely collected. Since this information was not available, proxy information on this outcome indicator will be reported that relies on available data from the preand post-test surveys.

The following two proxy indicators were developed for both pre-test and post-test measurements:

- Indicator 1: percentage of women who came to receive postpartum services relative to those who came for the first antenatal visit for the index pregnancy.

- Indicator 2: percentage of women who came to receive postpartum services having received antenatal care in the same clinic for the index pregnancy relative to those who came for their first antenatal visit for the index pregnancy.

Table 10 shows values of these proxy indicators in both pre-test and post-test studies. The first indicator increased approximately 10 percentage points (almost double) from 12.9 percent in the pre-test to 22.7 percent in the post-test and the difference is statistically significant $(\mathrm{P}<0.01)$. The second indicator increased from 10.5 percent in the pre-test to 17.2 percent in the post-test, but the difference is not statistically significant.

Additional insights into the use of postpartum services are provided in Figure 2 which shows the purpose of the visit. At the time of the post-test, more women reported that they were seeking care for themselves (about 51\% compared to about $44 \%$ in the pre-test survey), while fewer women reported visiting the clinic for the "baby only" (about $11 \%$ compared to about
Table 10: Proxy Indicators on the First Outcome Indicator

\begin{tabular}{|l|c|c|}
\hline & Pre (\%) & Post (\%) \\
\hline${\text { Indicator } 1^{\mathrm{a}}}^{\mathrm{b}}$ & 12.9 & $22.7^{*}$ \\
\hline${\text { Indicator } 2^{\mathrm{b}}}^{\mathrm{b}}$ & 10.5 & 17.2 \\
\hline
\end{tabular}

${ }^{\text {a }}$ Indicator 1: Percent of women who came to receive postpartum services relative to those who came for the first antenatal visit for the index pregnancy

${ }^{\mathrm{b}}$ Indicator 2: Percent of women who came to receive postpartum services and have received antenatal care in the same clinic for the index pregnancy relative to those who came for their first antenatal visit for the index pregnancy

$* \mathrm{P}<0.01$

Source: client exit interview 


\title{
Figure 2: Postpartum Clients Checked at the Visited Clinic:
}

\author{
Are you coming today for a health exam for yourself or the
}
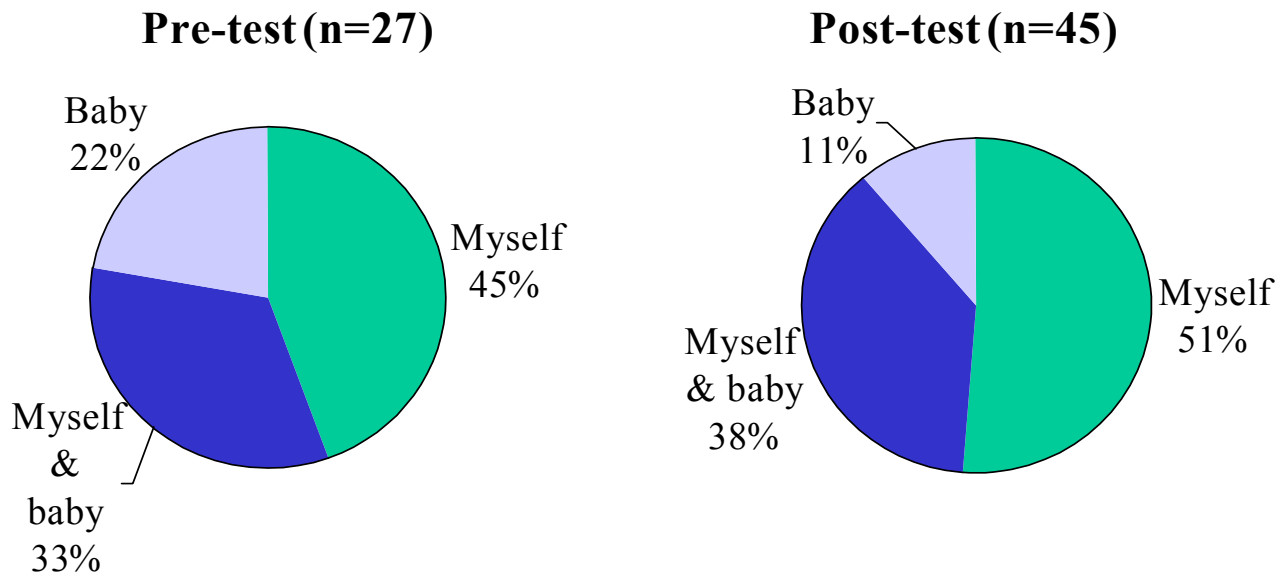

Source: client exit interview

$22 \%$ in the pre-test survey). The most commonly reported reasons for postpartum visits in both the pre-test and post-test phases were to receive postpartum care, to receive well-baby check-ups, to give the baby immunizations, to receive advice for care of the baby, and to receive counseling on family planning or a method. Because of the small sample size, the differences between the pre- and post-test surveys are not statistically significant, but the direction of the change is suggestive of a positive impact on client health seeking behaviors.

Table 11 presents information on the antenatal care experience of postpartum women who came to PHP clinics to receive postpartum care. In the post-test survey, approximately three-quarters $(73.9 \%)$ of the women who came for postpartum care had received antenatal care for the index pregnancy at that PHP clinic, compared to 81.5 percent in the pre-test survey. The proportion of women with between four and six or seven and 10 visits increased in the posttest survey. Also, only about 12 percent of women in the post-test had less than the WHO recommended four visits. However, the postpartum of women receiving 11 or more antenatal visits declined from about 32 percent in the pre-test to less than 10 percent Table 11: Antenatal Care Experience of Women Receiving Postpartum Care

\begin{tabular}{|c|c|c|}
\hline \multicolumn{3}{|c|}{ 1. \% Received ANC in this clinic } \\
\hline & Pre-test & Post-test \\
\hline & $81.5(n=27)$ & $73.9(n=45)$ \\
\hline \multicolumn{3}{|c|}{ 2. No. of ANC visits to this clinic (\%) } \\
\hline No. of visits & Pre-test & Post-test \\
\hline $1-3$ & 18.2 & 11.8 \\
\hline $4-6$ & 22.7 & 41.2 \\
\hline $7-10$ & 27.3 & 38.2 \\
\hline $11-12$ & 18.2 & 5.9 \\
\hline $13+$ & 13.6 & 2.9 \\
\hline
\end{tabular}

Source: client exit interview in the post-test. 


\section{Obstetrical Service Utilization of Postpartum Clients}

Women who attended the clinic for a postpartum visit were asked about their most recent birthing experience in terms of place of delivery, length of stay at the hospital, postpartum attendance by health care professionals and postpartum home visits. However, it is important to note that differences between the pre-test and post-test surveys should be interpreted with caution because of the very small numbers of women seeking postpartum care, (pretest: $n=27$, or $3.4 \%$ of the entire sample/post-test: $\mathrm{n}=45$, or $4.2 \%$ of the entire sample). The small numbers of cases also constrained ability to detect statistically significant differences.

In the post-test survey, as in the pre-test survey, the large majority of the postpartum women interviewed reported having given birth at a hospital (Table 12). The proportion of home deliveries $(13 \%)$, is higher than the national average of 5.2 percent $(7.7 \%$ in the West Bank and $0.8 \%$ in Gaza) ${ }^{12}$. This difference could be due to the fact that the populations under study (PHP) reside in villages and may therefore have less access to hospitals. In addition, this finding might support anecdotal evidence of more women giving birth at home because of the current
Table 12: Use of Obstetrical Service among PHP Postpartum Clients

\begin{tabular}{|c|c|c|}
\hline Services & Pre $(\%)$ & Post (\%) \\
\hline - Where did you deliver index baby? & $\mathbf{n}=\mathbf{2 7}$ & $n=45$ \\
\hline Hospital & 85 & 87 \\
\hline At home & 11 & 13 \\
\hline Health clinic & 4 & - \\
\hline $\begin{array}{l}\text { - How long have you stayed at hospital after } \\
\text { index delivery? }\end{array}$ & $\mathbf{n}=\mathbf{2 3}$ & $\mathbf{n}=\mathbf{3 9}$ \\
\hline $1-4$ hours & 30 & 28 \\
\hline 5-12 hours & 35 & 8 \\
\hline 13-24 hours & 22 & 44 \\
\hline $25+$ & 13 & 20 \\
\hline $\begin{array}{l}\text { - When were you first seen by a health } \\
\text { provider after index delivery? }\end{array}$ & $\mathbf{n}=\mathbf{2 7}$ & $n=43$ \\
\hline 1-4 days & 26 & 49 \\
\hline 5-10 days & 30 & 25 \\
\hline 11-29 days & 22 & 7 \\
\hline $30+$ days & 22 & 19 \\
\hline $\begin{array}{l}\text { - Where were you first seen by health provider } \\
\text { after index delivery? }\end{array}$ & $n=26$ & $n=43$ \\
\hline At this clinic & 58 & 30 \\
\hline Private physician / hospital & 19 & 47 \\
\hline UNRWA / MOH & 15 & 16 \\
\hline Home visit & 8 & 7 \\
\hline $\begin{array}{l}\text { - Were you visited at home by a health } \\
\text { provider after index delivery? }\end{array}$ & $\mathbf{n}=\mathbf{2 7}$ & $n=42$ \\
\hline Yes & 33 & 29 \\
\hline $\begin{array}{l}\text { - After how many days since delivery were you } \\
\text { visited at home? }\end{array}$ & $\mathrm{n}=9$ & $n=15$ \\
\hline $1-2$ days & 22 & 13 \\
\hline 3-7 days & 45 & 47 \\
\hline $8+$ days & 33 & 40 \\
\hline - Visited by whom? & $\mathrm{n}=\mathbf{9}$ & $n=15$ \\
\hline CHW & 67 & 73 \\
\hline Nurse & 44 & 27 \\
\hline Physician & 33 & - \\
\hline $\begin{array}{l}\text { - How many times did you visit the clinic after } \\
\text { the index delivery? }\end{array}$ & $n=7$ & $n=45$ \\
\hline One visit & 70 & 82 \\
\hline Two visits & 26 & 11 \\
\hline Three visits & 4 & 7 \\
\hline $\begin{array}{l}\text { - Age of the newborn in days at the time of the } \\
\text { index postpartum visit }(\%)\end{array}$ & $\mathbf{n}=\mathbf{2 7}$ & $\mathrm{n}=\mathbf{4 2}$ \\
\hline$<15$ days & 22 & 17 \\
\hline 15-29 days & 26 & 21 \\
\hline 30-39 days & 37 & 36 \\
\hline 40 days & 7 & 12 \\
\hline $41+$ & 7 & 14 \\
\hline
\end{tabular}

Source: client exit interview 
difficulties with transportation and crossing checkpoints associated with the Al-Aqsa Intifada. Of the women who delivered in a hospital, almost two-thirds stayed in the hospital 13 hours or more, compared to only about one-third in the case of the pre-test.

Again, this may be due to the security situation in the PHP communities and may not be a reflection of the care giving process. Overall, in the post-test survey, more women appear to have been seen by a health provider sooner after the index delivery than in the pre-test. There was an almost 13 percent increase in the number of postpartum women seen by a health provider within four days of delivery, which could be suggestive of a positive impact by the PHP.

Women in the post-test survey seemed to be coming to the clinic for the postpartum visit later than women in the pre-test survey, with about 26 percent (compared to about $14 \%$ in the pre-test survey) reporting visiting the clinic at day 40 or beyond following delivery (Table 12). This may be due to the security situation and the irregular functioning of the clinics.

There was no significant difference in the number of women who reported receiving a postpartum home visit between the two surveys, and most women in both surveys reported being visited between three and seven days after delivery. As in the pre-test survey, most of the home visits were conducted by CHWs.

Despite the fact that home visits by CHWs to women after delivery did not increase in the posttest, there is some evidence that the number of activities conducted during these home visits did increase (not shown in Table 12). For example, women in the post-test were more likely to report that the CHW checked both their health and the baby's health, and provided health education messages (including information on breastfeeding) than were women in the pre-test surveys. Other activities conducted in both pre- and post-test surveys included examination of the baby's umbilical cord, taking the baby's temperature and measuring physical development, inquiring about exercise and personal hygiene, and performing chest, breast and abdominal examination of the mother.

In the post-test survey, some additional questions were added on whether postpartum women who received home visits during the postpartum period found those visits useful and, if yes, how so. Women who received a postpartum visit were remarkably consistent in providing positive feedback. About two-thirds of women in this group indicated that postpartum home visits were "very useful" and one-third indicated that those visits were "useful" (results not shown in Table 12). Most commonly reported reasons were that women received useful information on breastfeeding, as well as on maternal and baby nutrition, the baby's health was checked, and the home visit provided the opportunity to inquire on any health problem for the mother or the baby. All postpartum women who received a home visit answered affirmatively that the $\mathrm{CHW}$ encouraged them to make a return visit to the clinic at day 40 . 


\section{Indicator 2: Percentage of mothers who accept a family planning method out of those who made return visits to the clinic}

The results in Table 13 show that women were less likely to go to receive family planning counseling or methods in the post-test, compared with the pre-test survey.

Among those few women who did receive a postpartum contraceptive method, the majority went to the clinic after 30-40 days of delivery to receive the method as shown in Box 2.
Table 13: Postpartum Women Who Came to PHP Clinics to Receive FP Counseling and Methods

\begin{tabular}{|l|c|c|}
\hline & $\begin{array}{c}\text { Pre (\%) } \\
(\mathbf{n = 2 7 )}\end{array}$ & $\begin{array}{c}\text { Post (\%) } \\
(\mathbf{n = 4 5 )}\end{array}$ \\
\hline Came to receive counseling or method & 52 & 31 \\
\hline Came to receive method & 41 & $16^{*}$ \\
\hline $\mathrm{n}$ & 27 & 45 \\
\hline *P $<0.05$ & \multicolumn{2}{|l}{} \\
Source: client exit interview &
\end{tabular}
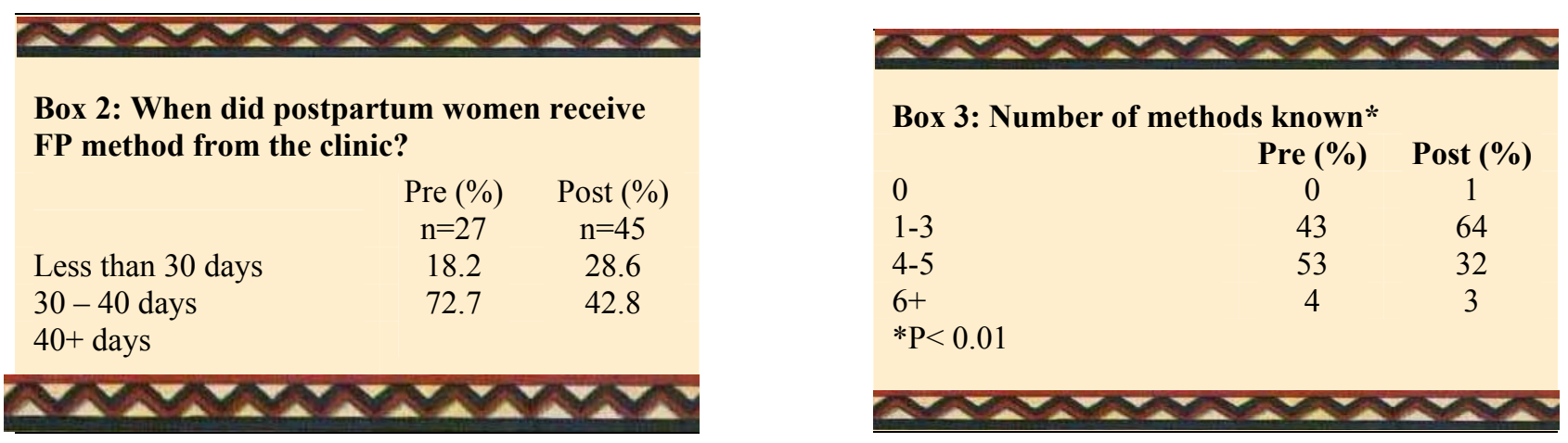

\section{Knowledge and Practice of Family Planning Methods}

Both the pre-test and post-test surveys examined clients' knowledge and practice of family planning methods. The results on knowledge of family planning methods among PHP clients are presented in Figure 3. This shows that the most frequently known modern methods are IUDs and pills. There seems to be some decline in the proportion of women reporting knowledge of individual family planning methods in the post-test survey compared with the pre-test, (although these differences are not statistically significant). Box 3 shows the number of methods known by women.

The results presented in Table 14 clearly show dramatic changes in the proportion of women who report ever or current use of a contraceptive method. A larger proportion of women in the post-test survey than in the pre-test survey reported ever using any method of family planning or ever using a modern method. Approximately two-thirds of the women interviewed in the posttest survey reported ever using any family planning method, and a little less (about 62\%) reported ever using a modern method. As for the methods ever used, the IUD is the most commonly used method for family planning, in line with the national pattern, followed by pills 


\section{Figure 3: Knowledge of Family Planning Methods Among Ever-Married Women (\%)}

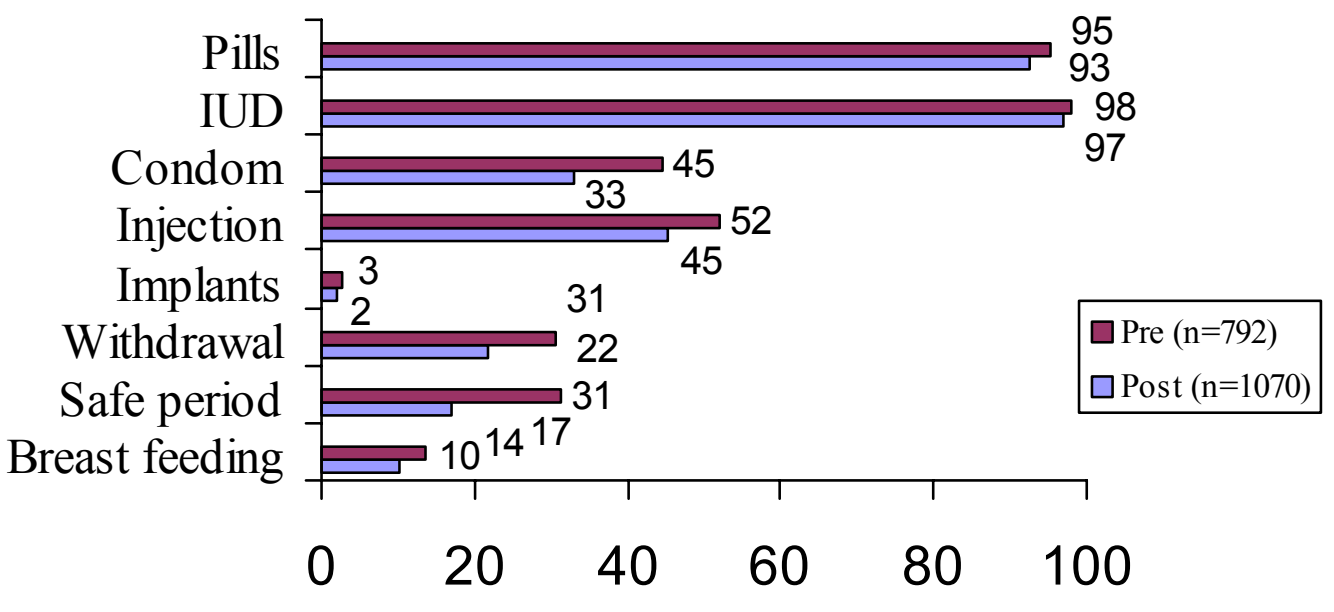

Source: client exit interview

Table 14: Past and Current Use of Family Planning Methods

\begin{tabular}{|l|c|c|}
\hline Aspect of use (\%) & Pre & Post \\
\hline Ever used any method & $57.4(\mathrm{n}=792)$ & $64.8^{*}(\mathrm{n}=1070)$ \\
\hline Ever used any modern method & 51.6 & $61.5^{* *}$ \\
\hline Methods ever used & & \\
IUD & 66.6 & 76.1 \\
Pills & 42.4 & 40.7 \\
Condoms & 17.4 & 12.2 \\
Injection & 6.4 & 6.9 \\
Norplant & 13.8 & 0.7 \\
Withdrawal & 3.3 & 10.5 \\
Breastfeeding & 11.2 & 4.9 \\
Safe period & $14.4(\mathrm{n}=792)$ & $32.3^{* *}(\mathrm{n}=1070)$ \\
\hline Currently using any method & 13.9 & $31.6^{* *}$ \\
\hline Currently using a modern method & & \\
\hline Methods currently used & 70.9 & 74.9 \\
IUDs & 11.1 & 3.3 \\
Injection & 10.3 & 12.3 \\
Pills & 1.7 & 3.6 \\
Condoms & 5.1 & 4.5 \\
Safe period & - & 1.1 \\
Withdrawal & 0.9 & 0.3 \\
Other & $2.9(\mathrm{n}=426)$ & $2.8(\mathrm{n}=514)$ \\
\hline Mean number of children at first use & $24.6(\mathrm{n}=458)$ & $23.9(\mathrm{n}=692)$ \\
\hline Mean age at first use & \multicolumn{2}{|}{} \\
*P $<0.05$ & \multicolumn{2}{|l}{} \\
**P $<0.01$ & & \\
Source: client exit interview &
\end{tabular}


and condoms. Withdrawal, the safe period, and breastfeeding were reported as traditional family planning methods used, although ever used by fewer women (Table 14).A substantial and highly significant increase in proportion of women who reported current use of family planning methods is shown. The proportion of women in the post-test survey currently using any method or any modern method was more than double the corresponding proportion in the pre-test survey (about 32 versus $14 \%$ respectively, Table 14).

It should be noted that the substantial increase in percentage of users among all women in the post-test reflects the larger proportion of women who visited the PHP clinics for reasons other than receiving antenatal care in the post-test survey (37\%), compared to the pre-test survey (17\%). Specifically, percent of women who came to receive family planning services increased from 15 to 33 percent and the percent of women who came to receive postpartum care increased from 2 to 4 percent between the two surveys. Considering these two groups of women, current use slightly increased from 84 to 86 percent between the two surveys.

Among current users, the most frequently used method was the IUD. There was also a slight increase in the proportion of women using pills and condoms. The proportion of women reporting current use of condoms for family planning doubled from 1.7 to 3.6 percent between the two surveys, though the actual numbers (percent and real) are quite low. On the other hand, the proportion of women reporting current use of injectables dropped substantially between the two surveys. Reasons for this sharp drop should be examined.

The mean number of children the women had at the time of first use was nearly same between the two surveys while the mean age of the woman at the time of first contraceptive use slightly declined in the post-test compared with the pre-test, (not significantly, however).

\section{Indicator 3: Percentage of low parity women (1-2 living children) accepting a family planning method.}

An important element of the PHP intervention activities was to develop an emphasis on reaching low parity women (with 1-2 living children) with information and services tailored to meet their special needs. These activities focused, in large part, on highlighting the health benefits for both mothers and children of spacing children. A special operations research study has been designed and implemented under the PHP to achieve this objective (Center for Development in Primary Health Care (CDPHC), 2002) "Improving Postpartum Care Among Low Parity Mothers in Palestine". The pre- and post-test study results also provide information on this key outcome indicator.

Table 15 shows data on women currently using family planning methods by the number of living children they have. These results clearly show that the proportion of women who currently use family planning methods increased for each category of living children between the pre- and post-test surveys. Of particular importance are the results on current use of a family planning method among low parity Table 15: Among Women Having the Specified Number of Living Children, Percent Currently Using Any FP Method*

\begin{tabular}{|l|c|c|}
\hline Living Children & $\begin{array}{c}\text { Pre (\%) } \\
(\mathrm{n}=792)\end{array}$ & $\begin{array}{c}\text { Post (\%) } \\
(\mathrm{n}=1.070)\end{array}$ \\
\hline 0 & 0.0 & 0.9 \\
$1-2$ & 6.5 & 28.8 \\
$3-4$ & 17.7 & 35.2 \\
$5+$ & 29.9 & 51.0 \\
\hline $\mathrm{n}$ & 792 & 1070 \\
\hline
\end{tabular}
women. The percentage of low parity women using

$* \mathrm{P}<0.001$

Source: client exit interview 
family planning methods increased four-fold from about 7 percent in the pre-test to about 29 percent in the post-test, $(\mathrm{P}<0.01)$.

Figure 4 shows the percentage distribution of current users by number of living children and provides further evidence of increased family planning use among low parity women in the post-test compared with the pre-test. The percentage of low parity women (1-2 living children) currently using a contraceptive method in the post-test survey was double that of the pretest survey ( 30 versus $15 \%$ respectively).

\section{Figure 4: Percentage Distribution of Current Family Planning Users by Number of Living Children*}

Pre-test $(n=114)$

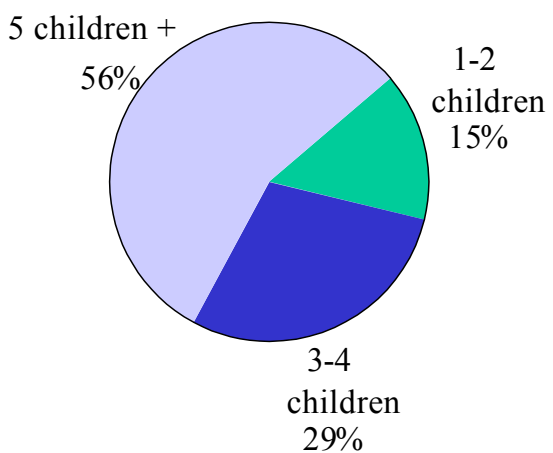

$* \mathrm{P}<0.01$

Source: client exit interview

\section{Indicator 4: Women's knowledge of antenatal and postpartum warning signs} for mothers and their babies

One of the major PHP objectives was to promote health seeking practices among Palestinian women and their children. An important step towards achieving this objective is promoting women's knowledge of antenatal and postpartum warning signs (both for mothers and for their babies).

Table 16 presents the principal results on women's knowledge of antenatal warning signs (told by service providers), which were collected through exit interviews. The findings indicate a modest to substantial increase in knowledge about ANC warning signs, with some differences being statistically significant. Knowledge level of ANC women, however, either did not change or even decreased for few other items in the post-test survey compared to the pre-test. Overall, it is remarkable to note that the percentage of ANC women who reported knowledge about all 12 of the ANC warning signs items increased more than four-fold from about 4 to about 17 percent in the post-test survey $(\mathrm{P}<0.01)$. However, that final proportion is still only about one-sixth of the women.

Figure 5 (below) presents the results on what postpartum women were told about warning signs in both pre-test and post-test surveys. Again, while knowledge of postpartum women about some postpartum warning signs substantially improved in the post-test compared with the pre-test survey (leg pain, leg edema and pelvic pain), knowledge about some other items either remained 


\section{Figure 5: Percent of Postpartum Women Who Were Informed About Postpartum Warning Signs (\%)}

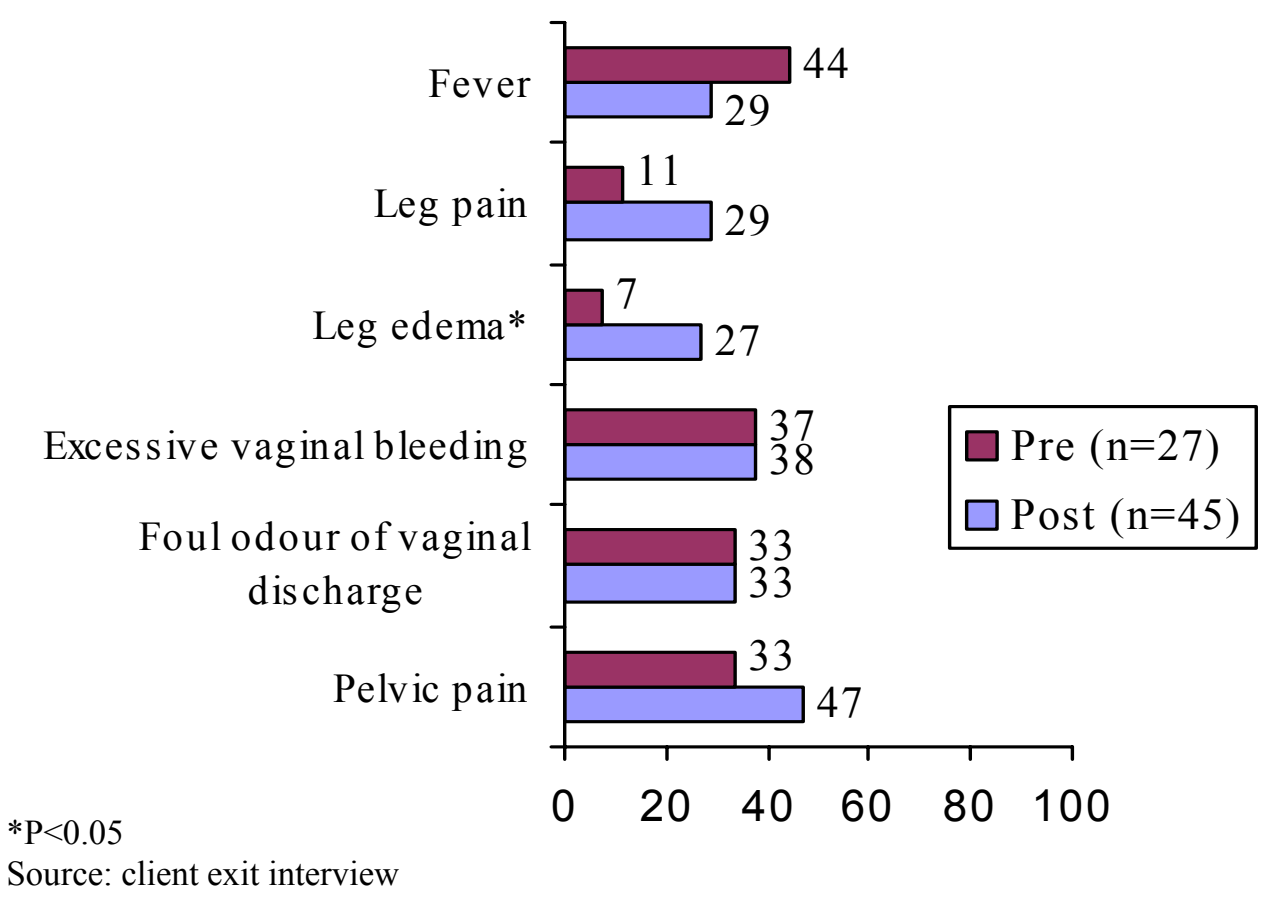

the same (excessive vaginal bleeding, foul odor of vaginal discharge) or even decreased (fever).

Overall, the proportion of women who reported knowledge about the majority of items of ANC and PP warning signs substantially increased as a result of the PHP (Figure 6). Specifically, the percentage of antenatal women who reported knowledge (as received from service providers) of 10 or more antenatal warning signs increased from about 9 percent in the pre-test to about 20 percent in the post-test $(\mathrm{P}<0.01)$. Also, the percentage of postpartum women reporting being told of at least five postpartum warning sign items increased from about 4 percent in the pre-test to about 24 percent in the post-test $(\mathrm{P}<0.05)$. However, as Figure 6 demonstrates, no success has been achieved in improving women's knowledge on

Table 16: Percent of Antenatal Women Who Were Informed by Service Providers About ANC Warning Signs

\begin{tabular}{|l|l|l|}
\hline Warning signs & $\begin{array}{l}\text { Pre (\%) } \\
(\mathrm{n}=655)\end{array}$ & $\begin{array}{l}\text { Post (\%) } \\
(\mathrm{n}=669)\end{array}$ \\
\hline Excessive vomiting & 35.6 & 37.1 \\
\hline Abnormal vaginal bleeding & 35.7 & 35.4 \\
\hline Abnormal vaginal discharge & 37.6 & 40.0 \\
\hline Headache & 37.3 & 36.0 \\
\hline Fever & 28.9 & 29.0 \\
\hline Excessive weight gain & 39.7 & $30.7^{*}$ \\
\hline Generalized excessive swelling & 34.7 & 29.8 \\
\hline Blurring of vision & 17.4 & $26.2^{*}$ \\
\hline Epigastric pain & 25.1 & $33.9^{*}$ \\
\hline Excessive lower abdominal colic & 30.2 & 31.4 \\
\hline Decrease fetal movement & 34.8 & 31.7 \\
\hline Convulsions & 15.5 & $26.0^{*}$ \\
\hline Informed about all 12 warning signs & 3.7 & $16.8^{*}$ \\
\hline
\end{tabular}
$* \mathrm{P}<0.01$

Source: client exit interview 
newborn warning signs during the PHP. In fact, there has been a decline in the percentage of women reporting being told about newborn warning signs from 30 percent in the pre-test to 5 percent in the post-test, the reasons for which should be investigated.

\section{Figure 6: Total Knowledge Score of ANC and PP Women on ANC, PP and Newborns Warning Signs Items (\%)}

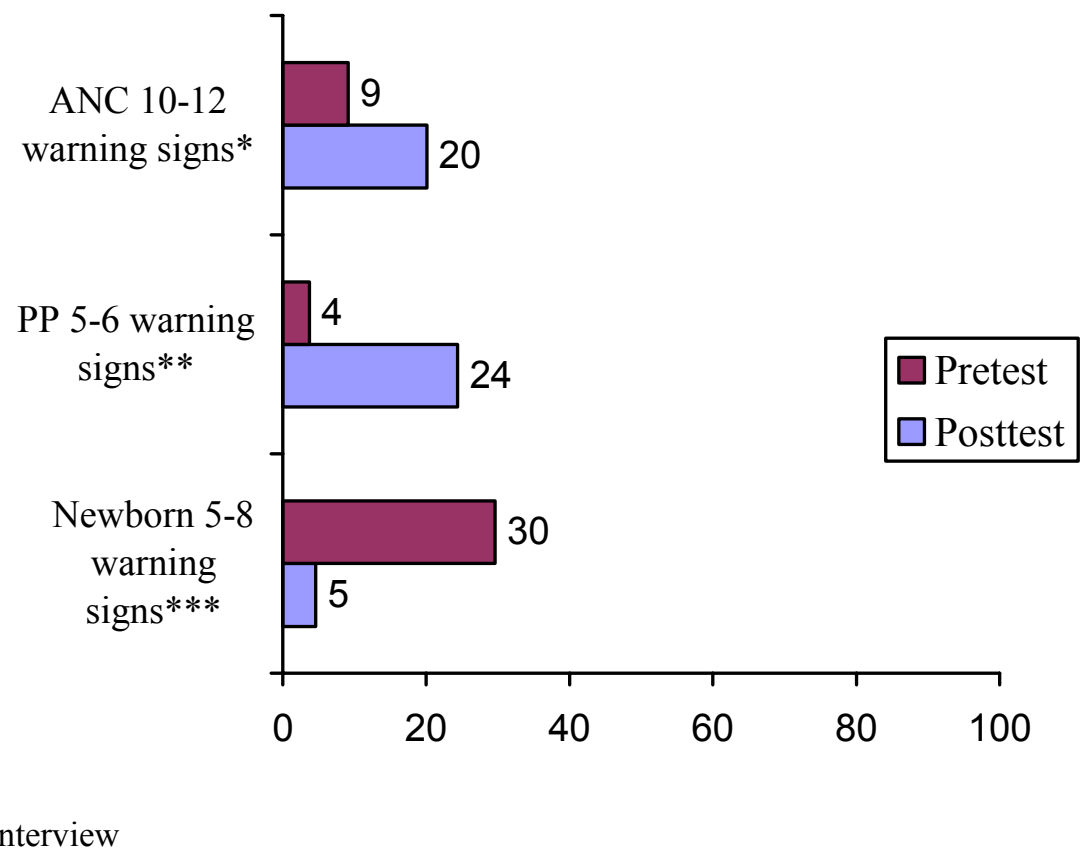

$* \mathrm{P}<0.01, * * \mathrm{P}<0.05$

Source: client exit interview

\section{FX] Indicator 5: Percentage of women seeking treatment in case of recognizing warning signs for themselves and their babies}

Women who received antenatal and postpartum care at PHP clinics also received information on warning signs that may occur during the ANC or PP periods (for mothers or babies). Follow up information given to women receiving health care for ANC or PP included the need to return promptly to the clinic for medical examination and treatment in case any of these warning signs were experienced.

Due to operational conditions, the data needed for this indicator were not collected in the pre-test survey. However, relevant questions were added to client exit interview forms in the post-test survey for direct measurement of this indicator. To provide pre-test estimates, proxy indicators from pre-test survey questions were designed and comparable items were also included in the post-test client interview form. 
ANC (and PP) women were asked about the timing of previous pregnancy (delivery), if any. The pregnancies (and deliveries) that occurred in a previous time period that corresponded roughly to conducting the pre-test survey (18-24 months ago) were screened. Relevant questions on this indicator were asked to those ANC and PP women.

Table 17 presents results on experiencing ANC warning signs and how the ANC women reacted. These findings show that a relatively small proportion of ANC women, ranging between 5 percent to about onequarter have experienced one or more of the ANC warning signs during their pregnancies, as reported in both the pre-test and post-test surveys. The most common warning signs experienced were abnormal vaginal discharge, headache, excessive vomiting and excessive lower abdominal colic. Almost all women sought treatment of these health conditions. The proportion of women who sought treatment in the post-test $(94 \%)$ is almost equal to the pre-test (93\%). More women in the post-test received treatment of the health condition (about 84.7\%) compared with women in the pre-test (about $81.8 \%$ ). But again, the difference is not statistically significant.

Nearly all women who sought treatment in the pre-test and posttest received treatment. Those few women who did not receive treatment reported that they were assured that they did not have a dangerous condition, or that treatment at that time was not advisable because of its impact on the condition of the fetus.
Table 17: Antenatal Women Reporting Experiencing ANC Warning Signs During Pregnancy and their Reaction

\begin{tabular}{|l|c|c|}
\hline & $\begin{array}{c}\text { ANC } \\
\text { Pre } \\
(\mathrm{n}=94)\end{array}$ & $\begin{array}{c}\text { ANC } \\
\text { Post } \\
(\mathrm{n}=669)\end{array}$ \\
\hline $\begin{array}{l}\text { 1. Have you experienced any of the } \\
\text { following health problems during }\end{array}$ & & \\
your pregnancy? (\% yes) & & \\
Warning signs experienced: & & \\
Excessive vomiting & 19.1 & 22.0 \\
Abnormal vaginal bleeding & 7.4 & 7.8 \\
Abnormal vaginal discharge & 20.2 & 23.6 \\
Headache & 21.3 & 26.9 \\
Fever & 9.6 & 7.0 \\
Generalized excessive weight gain & 6.4 & 5.7 \\
Excessive swelling & 12.8 & 6.4 \\
Blurring of vision & 8.5 & 9.0 \\
Epigastric pain & 18.1 & 21.5 \\
Excessive lower abdominal colic & 19.1 & 23.2 \\
Decrease fetal movement & 3.2 & 5.8 \\
Convulsions & 9.6 & 7.6 \\
\hline 2. What did you do? & & \\
I sought treatment (\%) & 93.1 & 94.0 \\
& $(\mathrm{n}=41)$ & $(\mathrm{n}=350)$ \\
\hline 3. Did you receive treatment for this & & \\
condition? & & \\
Yes (\%) & & \\
& & \\
\hline Source: clent exit interview & & \\
$(\mathrm{n}=350)$ \\
\hline
\end{tabular}

Source: client exit interview

Table 18: Postpartum Women Reporting Experiencing PP Warning Signs and their Reactions

\begin{tabular}{|l|c|c|}
\hline & $\begin{array}{c}\text { PP } \\
\text { Pre (n=5) }\end{array}$ & $\begin{array}{c}\text { PP } \\
\text { Post (n=45) }\end{array}$ \\
\hline $\begin{array}{l}\text { 1. Have you experienced any health } \\
\text { problems during your postpartum } \\
\text { period? (\% yes) }\end{array}$ & & \\
Warning signs experienced & & \\
Fever & - & 8.9 \\
Leg pain & 20.0 & 15.6 \\
Leg edema & - & 4.4 \\
Vaginal bleeding & 20.0 & 8.9 \\
Foul odor discharge & 20.0 & 15.6 \\
Pelvic pain & 20.0 & 44.4 \\
\hline 2. What did you do? & & \\
I sought treatment (\%) & $100.0(\mathrm{n}=2)$ & $100.0(\mathrm{n}=26)$ \\
\hline 3. Did you receive treatment for this & & \\
condition? & $100.0(\mathrm{n}=2)$ & $92.3(\mathrm{n}=26)$ \\
Yes (\%) & & \\
\hline
\end{tabular}

Source: client exit interview 
Similar data on experiencing postpartum warning signs are presented in Table 18. The analysis presented in this table is based on a very small number of women (as indicated earlier). Among postpartum women in the pre-test, those who had a previous delivery during the period of time that corresponds to the pre-test data collection are very few (only five women). About 26 women out of the 45 postpartum women in the post-test have experienced one or more postpartum warning signs. As shown in these results, suffering from pelvic pain was the most common PP warning sign experienced by postpartum women (this health problem was reported by about onehalf of them). Suffering from leg pain and foul smelling discharge were the next most prevalent. All women who experienced PP warning signs sought and received the treatment needed.

\section{Indicator 6: Women's knowledge and practice of self-breast examination and Pap smear tests.}

The results shown in Table 19 reveal that fewer antenatal women reported being told how to conduct self-breast examinations on a regular basis in the post-test survey than in the pre-test survey (pre: about $35 \%$, post: about $27 \%$ ), even though the proportion of women who conduct breast self-exams increased significantly. However, the findings show that of women who were informed about this examination, a higher percentage reported that their source of knowledge was the PHP clinic (pre: about $21 \%$, post: about $60 \%$ ) and that they were conducting it on regular basis (pre: about $41 \%$, post: about $60 \%$ ). The same result applies to postpartum women.

Table 20 presents data on conducting pap smear tests among ANC women who are aged 35 years or older. In the post-test survey, there was an increase (though statistically insignificant) in the proportion of ANC women aged 35 years and older who reported ever receiving a pap smear (about $18 \%$ compared to $11 \%$ in the pre-test survey). However, a smaller proportion of those women had the pap smear test done at the PHP clinic in which they were interviewed (Table 20).
Table 19: Knowledge and Practice of Breast-Self Examination, Antenatal and Postpartum Women

\begin{tabular}{|l|c|c|}
\hline A. Antenatal Women & Pre & Post \\
\hline 1. Do you know how to conduct breast-self & & \\
examination? & $(\mathrm{n}=653)$ & $(\mathrm{n}=659)$ \\
Yes (\%) & 35.4 & $27.3 *$ \\
\hline 2. Source of knowledge (\%) & $(\mathrm{n}=231)$ & $(\mathrm{n}=180)$ \\
This clinic & 71.2 & $59.9 *$ \\
Another clinic & & 40.1 \\
\hline 3. Do you conduct breast-self examination & & \\
on regular basis? & 40.7 & $59.9 *$ \\
Yes (\%) & Pre & Post \\
\hline B. Postpartum Women & $(\mathrm{n}=27)$ & $(\mathrm{n}=44)$ \\
\hline 1. Do you know how to conduct breast-self & 44.4 & 36.4 \\
examination? & $(\mathrm{n}=15)$ & $(\mathrm{n}=16)$ \\
Yes $(\%)$ & 25.0 & $81.3 * *$ \\
\hline 2. Source of knowledge (\%) & 75.0 & 18.7 \\
This clinic & & \\
Another clinic & & \\
\hline 3. Do you conduct breast-self examination & & \\
on regular basis? & & \\
Yes (\%) & & \\
*P $<0.01$ & & \\
** $<0.05$ & & \\
Source: client exit interview & & \\
\hline
\end{tabular}

Table 20: Pap Smear Tests Among Antenatal Clients (35 years old and above)

\begin{tabular}{|l|c|c|}
\hline & Pre & Post \\
\hline 1. Have you received a Pap smear test? & $(\mathrm{n}=70)$ & $(\mathrm{n}=63)$ \\
Yes (\%) & 11.4 & 17.5 \\
\hline 2. Where did you have the test done? $(\%)$ & $(\mathrm{n}=8)$ & $(\mathrm{n}=11)$ \\
In this clinic & 75.0 & 63.6 \\
Another health facility & 25.0 & 36.4 \\
\hline
\end{tabular}

Source: client exit interview 


\section{Indicator 7: Percentage of husbands and other males who are aware of the importance of at least 36 months birth interval, antenatal and postpartum care, and family planning use}

The pre-test indicators of husbands' awareness of the importance of antenatal care (as reported by their wives) were already very high in the pre-test and they appeared to be even higher, though marginally, in the post-test survey (Table 21). Husbands' belief in the importance of ANC and their encouragement for ANC visits were almost universal. Furthermore, almost all women (97\%) reported discussing the results of ANC visits with their husbands. Accompanying wives to the clinic for ANC services is, however, less frequent. As in the pre-test survey, a small proportion of women in the post-test reported that their husbands accompany them to ANC visits or that their husbands had accompanied them to the clinic on the day of the interview. This latter finding was also reflected by an operations research study under the PHP research activities ${ }^{14}$.

Women who went to PHP clinics to receive antenatal care who wanted more children were also asked during exit interviews how long they preferred to wait after delivery of the index pregnancy until the next birth. They also reported on their husbands' preferences for birth spacing (in case husbands wanted more children). In the pre-test survey more than one-half of both wives and husbands preferred to wait for at least three years. In the post-test survey, lower proportions of wives and husbands preferred to wait for at least three years (about 39 and 35, respectively) (Table 21).

As in the case of the pre-test survey, a large majority of women in the post-test (about 92\%) reported discussing the use of family planning with their husbands, and almost all of them agreed with their husbands on the decision to use family planning methods, (pre: 94\%, post: 97\%).

Table 21: Clients Reports on Husbands' Involvement

\begin{tabular}{|l|c|c|}
\hline Husbands' involvement in the following issues & Pre & Post \\
\hline Antenatal Care (\%) & $(\mathrm{n}=655)$ & $(\mathrm{n}=669)$ \\
Husband thinks that ANC is important for women's health & 98.0 & 99.4 \\
Husband encourages woman to go to antenatal clinic & 96.2 & 97.2 \\
Woman discusses with husband antenatal visit results & 96.2 & 97.0 \\
Husband goes with woman to antenatal visits (yes and sometimes) & 26.4 & 22.6 \\
Husband accompanied woman today to the clinic & $(\mathrm{n}=792) 5.6$ & $(\mathrm{n}=1070) 6.7$ \\
\hline Family Planning & $(\mathrm{n}=789)$ & $(\mathrm{n}=1069)$ \\
Discuss use of family planning with husband? Yes (\%) & 91.8 & 91.8 \\
Agree with husband about whether or not to use FP? Yes (\%)* & $(\mathrm{n}=725) 93.5$ & $(\mathrm{n}=982) 96.5$ \\
\hline Birth Spacing Preference among ANC women ${ }^{1}$ & $(\mathrm{n}=365)$ & $(\mathrm{n}=465)$ \\
\% Prefer to wait 2 years before next child & 31.5 & 34.9 \\
\% Prefer to wait at least 3 years before next child** & 57.7 & 38.5 \\
Mean no. of years desired before having next child & 3.1 & 2.5 \\
\hline Husbands of ANC women as reported by wives & $(\mathrm{n}=365)$ & $(\mathrm{n}=536)$ \\
\% Prefer to wait 2 years before next child & 30.7 & 31.3 \\
\% Prefer to wait at least 3 years before next child** & 57.2 & 34.5 \\
Mean no. of years desired before having next child & 3.2 & 2.4 \\
\hline 1 Among those who want more children & & \\
$*$ P $<0.05$ & & \\
$* *$ P $<0.01$ & & \\
Source: client exit interview & &
\end{tabular}




\section{Indicator 8: Knowledge and skills of all categories of health care providers}

Antenatal clients were asked if the health care providers enquired about their basic obstetric history. Each item was read during the interview and women indicated if the doctor had asked about it. Figure 7 displays ANC women's responses to these questions in the pre-test and post-test surveys. Overall, these findings show the PHP's positive impact on providers' clinical practice related to obstetrical history taking. More ANC women in the post-test reported that the health providers asked them about the specified obstetric history items than in the pre-test, and the differences are statistically significant with just a few exceptions. Box 4 indicates number of obstetric history items inquired about by health providers.

Table 22 provides additional insights on improvements in antenatal health care provided by the PHP.

Antenatal women were asked if the health team at the clinic performed any of the eight tasks that were read to them during their visit to the clinic that

\section{Figure 7 : Percent of Obstetric History Items Inquired About by the Health Care Providers During the Antenatal Visit}

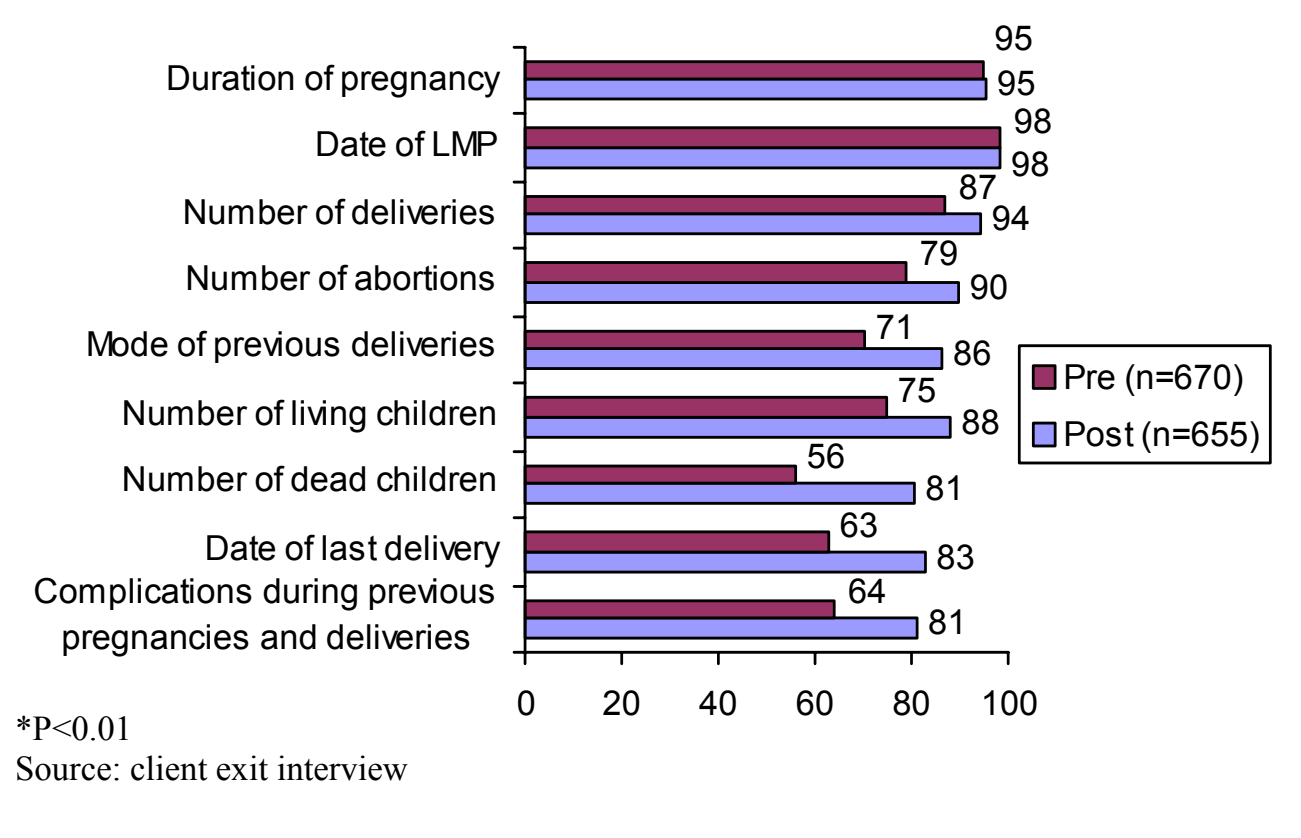
day. These tasks included checking blood pressure and weight, conducting heart, chest, breast and abdominal examination, fetal heart auscultation and lower limb examination. The results show that the percentage of women who had five to eight of the tasks performed as part of the examinations increased by approximately 60 percent between the pre-test $(16 \%)$ and the post-test $(26 \%)$ (the difference is statistically significant, $\mathrm{P}<0.01)$.

Table 22: Percent Distribution of Number of Tasks Performed by the Health Care Providers During Antenatal Examination*

\begin{tabular}{|l|c|c|}
\hline no. of tasks & Pre \% $(\mathrm{n}=655)$ & Post \% $(\mathrm{n}=419)$ \\
\hline $0-2$ & 12.3 & 2.1 \\
\hline $3-4$ & 71.8 & 71.6 \\
\hline $5-8$ & 16.0 & 26.2 \\
\hline
\end{tabular}

$* \mathrm{P}<0.01$

Source: client exit interview Items include: checking blood pressure and weight, conducting heart, chest, breast and abdominal examination, fetal heart auscultation and lower limb examination 
As in the case of antenatal women, postpartum women were asked in the exit interview to report on tasks performed by health providers during their postpartum visits (Table 23). The nine items include checking blood pressure, pulse and temperature, and conducting chest, heart, breast, abdominal, vaginal and lower limb examinations. Despite the small number of postpartum women, the results in Table 23 indicate women in the post-test survey were more likely to report that the health providers made a more complete health examination for them during the postpartum visit than women in the pre-test survey.
Table 23: Percent Distribution of Number of Tasks Performed by the Health Care Providers During Postpartum Examination*

\begin{tabular}{|l|c|c|}
\hline no. of tasks & Pre $\%(n=27)$ & Post $\%(n=45)$ \\
\hline $0-2$ & 70.3 & 40.0 \\
\hline $3-6$ & 29.6 & 40.0 \\
\hline $7-9$ & 0 & 20.0 \\
\hline
\end{tabular}

$* \mathrm{P}<0.01$

Source: client exit interview

Tasks include: checking blood pressure, pulse and temperature, conducting heart, chest, breast and abdominal, vaginal and lower limb examination,

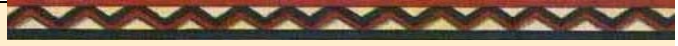

Box 4: Number of obstetric history items asked to ANC clients by health providers* Pre $(\%) \quad$ Post $(\%)$

$0-2 \quad 4.2 \quad 4.4$

$\begin{array}{lll}3-5 & 24.6 & 8.5\end{array}$

$\begin{array}{lll}6-8 & 32.4 & 15.3\end{array}$

$\begin{array}{lll}9 & 38.8 & 71.8\end{array}$

$* \mathrm{P}<0.01$
Forty percent of the postpartum women reported that between three to six tasks were done in the post-test, compared with about 30 percent in the pre-test. Also, 20 percent of the postpartum women reported receiving between seven to nine types of examination in the posttest, while virtually no postpartum women in the pretest reported receiving that range of tasks.

Nurses and CHWs were asked to report on the principal information items they usually provide to new family planning clients on family planning methods. Table 24 provides information on pre-test and post-test comparisons of the nurses and CHWs responses to this question. These findings show improvements in information given to new family planning clients, especially with regard to information on efficiency of the method and possible side effects. The results in Box 5 (below) show changes in a summative score on counseling developed using the results of Table 24. Nurses and CHWs who reported providing between one and three items on the family planning method increased from about 51 percent in the pre-test to about 59 percent in the post-test. Moreover, nurses and CHWs who reported providing all four of the counseling items increased from about 31 percent in the pre-test to about 41 percent in the post-test. These results clearly indicate that substantial and highly significant improvements were made by the PHP in the provision of information by nurses and CHWs.

Table 24: Nurses' and CHWs' Report on the Information that they Usually Provide to New Family Planning Clients

\begin{tabular}{|c|c|c|}
\hline Items & Pre $\%(n=45)$ & Post $\%(n=49)$ \\
\hline How the method works & 60.0 & 69.4 \\
\hline The efficiency of the method & 42.2 & $81.6^{*}$ \\
\hline The advantages of the method & 44.4 & 63.3 \\
\hline $\begin{array}{l}\text { The possible side effects of } \\
\text { the method }\end{array}$ & 80.0 & $93.3 * *$ \\
\hline
\end{tabular}


The post-test survey asked PHP providers to report on their impressions of the PHP activities. These results are presented in Table 25. About three-quarters of nurses and CHWs received training by the (CDPHC). Because of the high turnover rate among service providers in the West Bank and Gaza clinics (estimated at 20\%), some of the nurses and CHWs who replaced staff did not receive the CDPHC training. It is also possible that some nurses and CHWs were not available at the time that CDPHC training was provided (due to maternity leave, for example). Training was rated the highest by participants on relevance $(100 \%)$, improvement of performance (about 92\%), and improvement of case management (about 81\%). Approximately two-thirds of participants reported that training improved their job satisfaction and the quality of care. Among physicians, again, seven out of nine received the training provided by CDPHC. Virtually all of the physicians who received training indicated that it was highly relevant or relevant and most of them said during the interviews that the training promoted their performance, job satisfaction and improved case management.

CDPHC developed a number of behavior change communication (BCC) materials that supported the PHP objectives. These included six prototype materials: two posters (one for providers and one for clients) and a sticker on infection prevention; a fact sheet for clients on warning signs during pregnancy; and two client leaflets on gestational diabetes and postpartum care. The post-test survey included some questions to service providers on the extent to which those materials were useful to them (Table 26). The results show that the majority of nurses, $\mathrm{CHWs}$ and physicians reported using these BCC materials during their

Box 5: Counseling in family planning score (nurses and CHW)*
0

1-3 (incomplete)

4 (complete)

$* \mathrm{P}<0.01$

Items include: how the method works, the efficiency, the advantages and possible side effects of the method
Table 25: Reports of Service Providers on the Training Provided by CDPHC under PHP

\begin{tabular}{|c|c|}
\hline & Percent \\
\hline \multicolumn{2}{|l|}{ 1. Nurses and CHW ${ }^{1}$} \\
\hline Received CDPHC training (yes and partially) $(n=49)$ & 73.5 \\
\hline Training (very relevant and relevant) $(n=36)$ & 100.0 \\
\hline Promoted performance & 91.7 \\
\hline Promoted job satisfaction & 63.9 \\
\hline Improved quality of care & 63.9 \\
\hline Improved case management & 80.6 \\
\hline Do you think there were some topics missing? (no) & 91.7 \\
\hline \multicolumn{2}{|l|}{ 2. Physicians ${ }^{2}$} \\
\hline Received CDPHC training (yes and partially) $(n=9)$ & 77.8 \\
\hline Training (very relevant and relevant) $(n=7)$ & 100.0 \\
\hline Promoted performance & 71.4 \\
\hline Promoted job satisfaction & 71.4 \\
\hline Improved quality of care & 57.1 \\
\hline Improved case management & 71.4 \\
\hline
\end{tabular}

Source: ${ }^{1}$ Nurse and CHW interview

${ }^{2}$ Physician interview

Table 26: Reports of Service Providers on the BCC Materials Developed for the PHP

\begin{tabular}{|l|c|c|}
\hline & Nurses $/$ CHWs & Physicians $^{\mathbf{2}}$ \\
\hline $\begin{array}{l}\text { BCC materials useful? (very } \\
\text { useful and useful) }\end{array}$ & $88.6(\mathrm{n}=44)$ & $85.7(\mathrm{n}=7)$ \\
\hline $\begin{array}{l}\text { Improved abilities to provide } \\
\text { better services for clients (yes) }\end{array}$ & $90.9(\mathrm{n}=44)$ & $85.7(\mathrm{n}=7)$ \\
\hline $\begin{array}{l}\text { Materials developed for clients } \\
\text { used? (yes and sometimes) }\end{array}$ & $85.7(\mathrm{n}=49)$ & $77.8(\mathrm{n}=9)$ \\
\hline
\end{tabular}

Source: ${ }^{1}$ Nurse and CHW interview

${ }^{2}$ Physician interview 
consultations with clients and that these materials improved their abilities to provide better services to their clients.

\section{Indicator 9: Follow-up information given to antenatal and postpartum women on ANC and postpartum care including nutrition, hygiene, breastfeeding, and the need to use family planning.}

Overall, the results in Figure 8 show the PHP produced general improvement in giving follow-up information to antenatal clients in the post-test survey compared with the pre-test and most of these differences are statistically significant (Figure 8). More women reported being told about the outcome of their visit on that day, schedule of new visit, what to do in case of a warning sign, and the routine antenatal care schedule.

Antenatal women who visited PHP clinics were also asked to report on the information they received from health providers on aspects of ANC care (Table 27). These results indicate that there were some improvements in the information received by ANC clients regarding some information items, and the differences are statistically significant (personal hygiene, physical exercise, breast hygiene, smoking during pregnancy, natal care, newborn care, family planning). However, pregnant women were less likely to receive information in the post-test on adequate nutrition, how to

Figure 8: Percent of ANC Women Who Reported Being Told About Selected Aspects and Next Steps by Health Providers

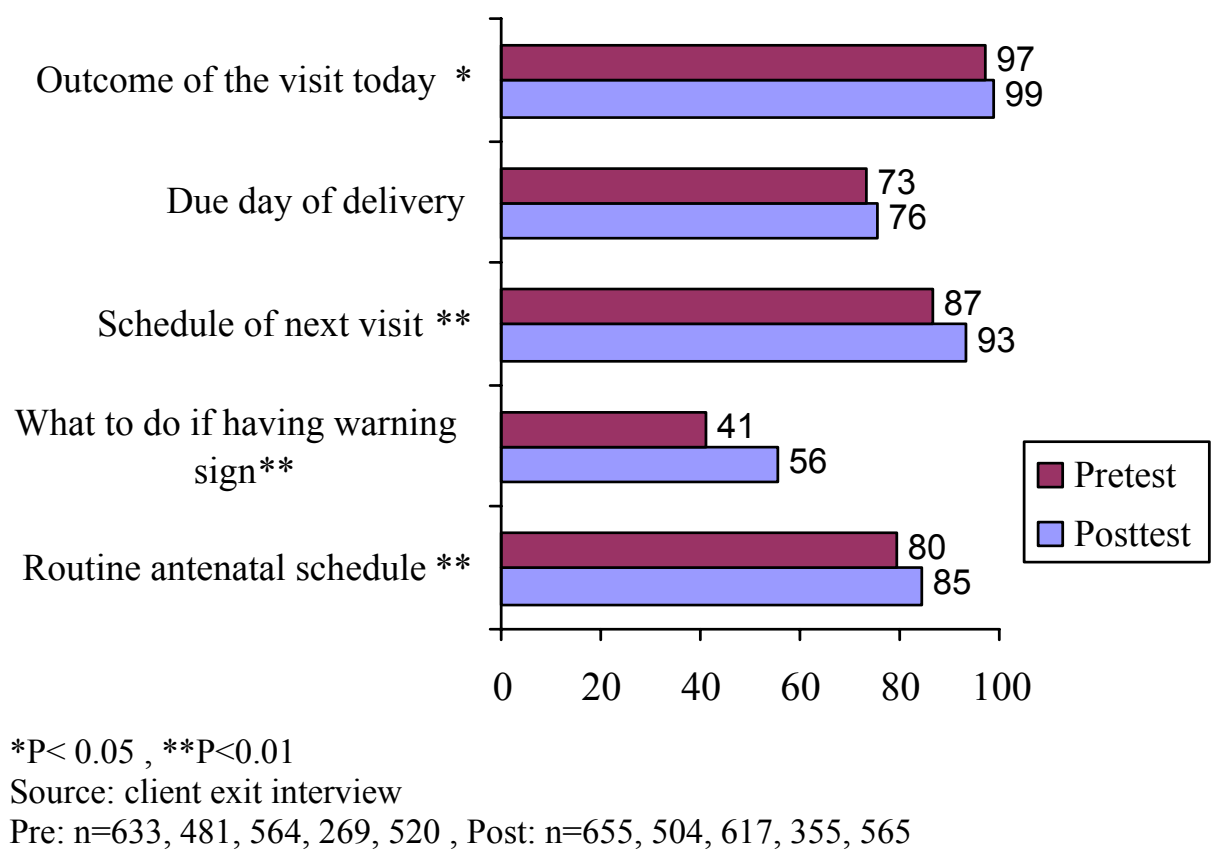

breastfeed, and benefits of breastfeeding, compared with the pre-test. Overall, there has been substantial increase in the percentage of ANC women who received information on all of the 12 ANC items in the posttest $(13 \%)$ compared with the pre-test $(2.6 \%)$. The difference is statistically significant $(\mathrm{P}<0.05)$. 
Postpartum women in the post-test were more likely to report that they received information on proper nutrition, personal hygiene, useful postpartum exercises and wound care than in the pretest (Table 28). However, these differences are not statistically significant due to the small number of cases. The proportion of postpartum women who reported receiving information on family planning methods, breastfeeding promotion and care of newborn declined from the pretest to post-test surveys, though the differences are not statistically significant. Again, it is worth noting that substantially more postpartum women reported receiving all nine postpartum information items in the post-test compared with the pre-test $(22.2 \%$ vs. $3.7 \%)$.

Substantial and highly significant improvements were achieved by the PHP on the provision of family planning information. Women who ever received a family planning method from the clinic were asked about the type of information they received at the time they received the method (Figure 9). With only one exception, more women in the posttest than in the pre-test reported receiving basic information on the family planning method received (how the method works, effectiveness, advantages, correct use of method, its side effects and what to do in case of experiencing complications of the method use). All differences are statistically significant $(\mathrm{P}<0.01)$. These findings indicate that improvements in counseling clients on family planning methods in the post-test compared with the pre-test have been substantial.
Table 27: Percent of ANC Clients Who Received Information from Health Providers on the Specified Items

\begin{tabular}{|l|c|c|}
\hline Follow up Items & $\begin{array}{c}\text { Pre } \\
(\mathrm{n}=655)\end{array}$ & $\begin{array}{c}\text { Post } \\
(\mathrm{n}=669)\end{array}$ \\
\hline Adequate nutrition & 64.2 & 62.9 \\
\hline Personal hygiene & 36.3 & $50.2^{* *}$ \\
\hline Physical exercise & 13.2 & $27.8^{* *}$ \\
\hline Breast hygiene & 21.4 & $36.8^{* *}$ \\
\hline Medication & 57.6 & 55.1 \\
\hline Tetanus vaccination & 49.9 & 49.9 \\
\hline Smoking on pregnancy & 22.2 & $33.7 * *$ \\
\hline Natal care & 25.0 & $32.0^{*}$ \\
\hline How to breast feed & 36.1 & 35.6 \\
\hline Benefits of breastfeeding & 37.1 & 36.0 \\
\hline Newborn care & 21.9 & $28.3 *$ \\
\hline Family planning & 26.0 & $31.9 *$ \\
\hline Received all ANC (12) information items & 2.6 & $13.0 *$ \\
\hline *P $<0.05, * * P<01$ & & \\
Source: client exit interview & & \\
\hline
\end{tabular}

Table 28: Percent of Postpartum Women Reporting Receiving the Specified Information from Health Providers

\begin{tabular}{|l|c|c|}
\hline Follow up Items & $\begin{array}{c}\text { Pre } \\
(\mathrm{n}=27)\end{array}$ & $\begin{array}{c}\text { Post } \\
(\mathrm{n}=45)\end{array}$ \\
\hline Proper nutrition & 40.7 & 51.1 \\
\hline Personal hygiene & 25.9 & 42.2 \\
\hline Postpartum exercise & 22.2 & 28.9 \\
\hline Wound care & 37.0 & 46.7 \\
\hline Family planning methods & 51.9 & 46.7 \\
\hline Breast feeding promotion & 51.9 & 48.9 \\
\hline Breast feeding advices & 55.6 & 51.1 \\
\hline Care of the newborn & 51.9 & 42.2 \\
\hline Medications & 44.4 & 44.4 \\
\hline All postpartum (9) information items* & 3.7 & 22.2 \\
\hline *P<0.05 & &
\end{tabular}

Source: client exit interview 
Figure 9: Among Women Who Ever Received Any Contraceptives From the Clinic, Percent Informed About:

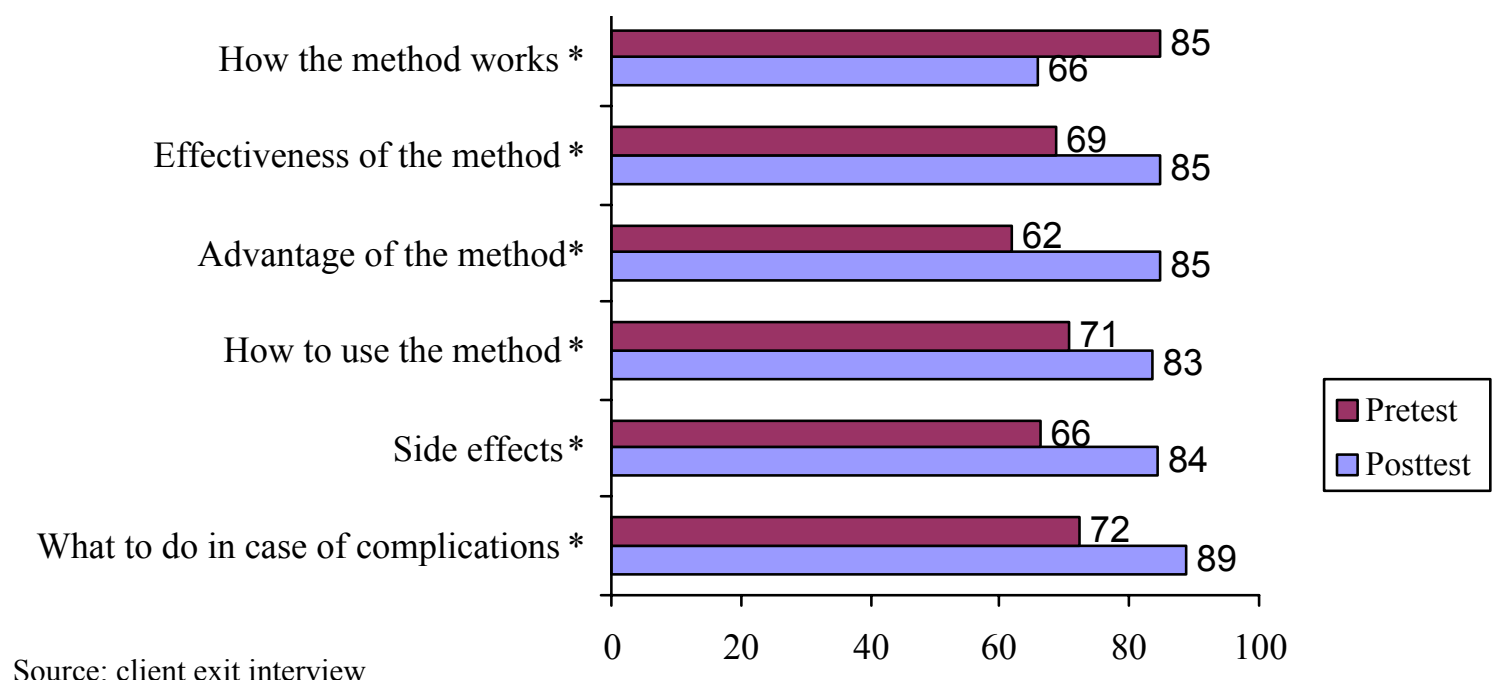

Source: client exit interview

Pre: $\mathrm{n}=119,124,112,128,120,130$

Post: $\mathrm{n}=298,297,297,292,293,311$

$\mathrm{P}<0.01$

\section{SELECTED INSIGHTS INTO QUALITY OF CARE AND ACCESSIBILITY}

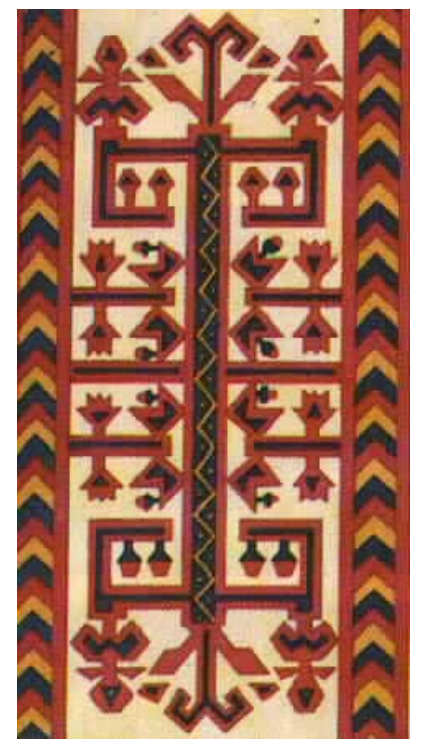

The pre-test and post-test surveys also collected data that provide additional insight on the quality of care provided in the PHP clinics as well as accessibility to these clinics. Those findings are presented below.

\section{Accessibility to PHP Clinics}

Throughout the PHP, accessibility (defined by geographical proximity) was high, despite the political unrest and difficulty with transportation. This may be explained by the fact that almost two-thirds of women reported needing less than 10 minutes to get to the clinic and threequarters said that they did not require transportation to go to the clinic (Table 29, below). Other dimensions of access, principally the availability of services (e.g., presence of provider) were less consistent, however. Nevertheless, the number of women who reported having 
made visits to the PHP clinic during the previous one to six months increased substantially from about one-fifth to almost two-fifths (Table 29, below).

\section{Quality of Care}

The findings from this study indicate that the quality of numerous aspects of service delivery were improved by the PHP. Indicators of quality of care were already high in the pre-test survey and became even higher in the post-test. Women in the post-test were more likely than in the pre-test to indicate that the physician explained procedures to them (post 97\%, pre $91 \%$ ) and that they were able to discuss all their concerns with him/her (post 97\%, pre 91\%). Furthermore, more clients in the post-test than in the pre-test reported that the physician respected their privacy and gave enough time for the consultation (Figure 10). These findings reflect improvement in a critically important dimension of quality: client-provider interaction. As a result, more women in the post-test reported during the exit interviews that they are "very satisfied" with services received (post 94\%, pre 90\%).

Additional aspects of quality of care are presented in Figure 11, which provides more evidence on improved quality of care as a result of the PHP. For all indicators of quality of care shown, more women in the post-test compared with the pre-test reported that they were welcomed in the clinic, received by a person who was helpful, that the clinic was clean and they were seated while waiting to receive services. Furthermore, more women in the post-test indicated that they did not wait a long time/ were served quickly. Almost all differences are statistically significant.

Finally, women in the post-test only were asked during exit interviews if they noted any physical changes in the clinic or services provided during the last 12-18 months. Those who answered affirmatively to this question were further asked to specify changes noted (Figure 12). Over onehalf of women (about 57\%) reported that they noted changes in the clinic or services offered. Most of changes noted were related to clinic renovation (about 69\%) and availability of new equipment (53\%). However, it is also remarkable that close to one-fifth of women $(18 \%)$ reported that they noted improvement in the health care provided and about equal proportion noted that health care providers provided better treatment. It is also interesting to note that about 14 percent of those women said that more services were made available (i.e., lab tests) and about one-tenth said that more educational materials are now available at the clinic. An overwhelming majority of the women (94\%) said that those changes encouraged them to make more visits to the clinic (not shown in the figure). 


\section{Figure 10: Quality of Care: Client-Provider Interaction}

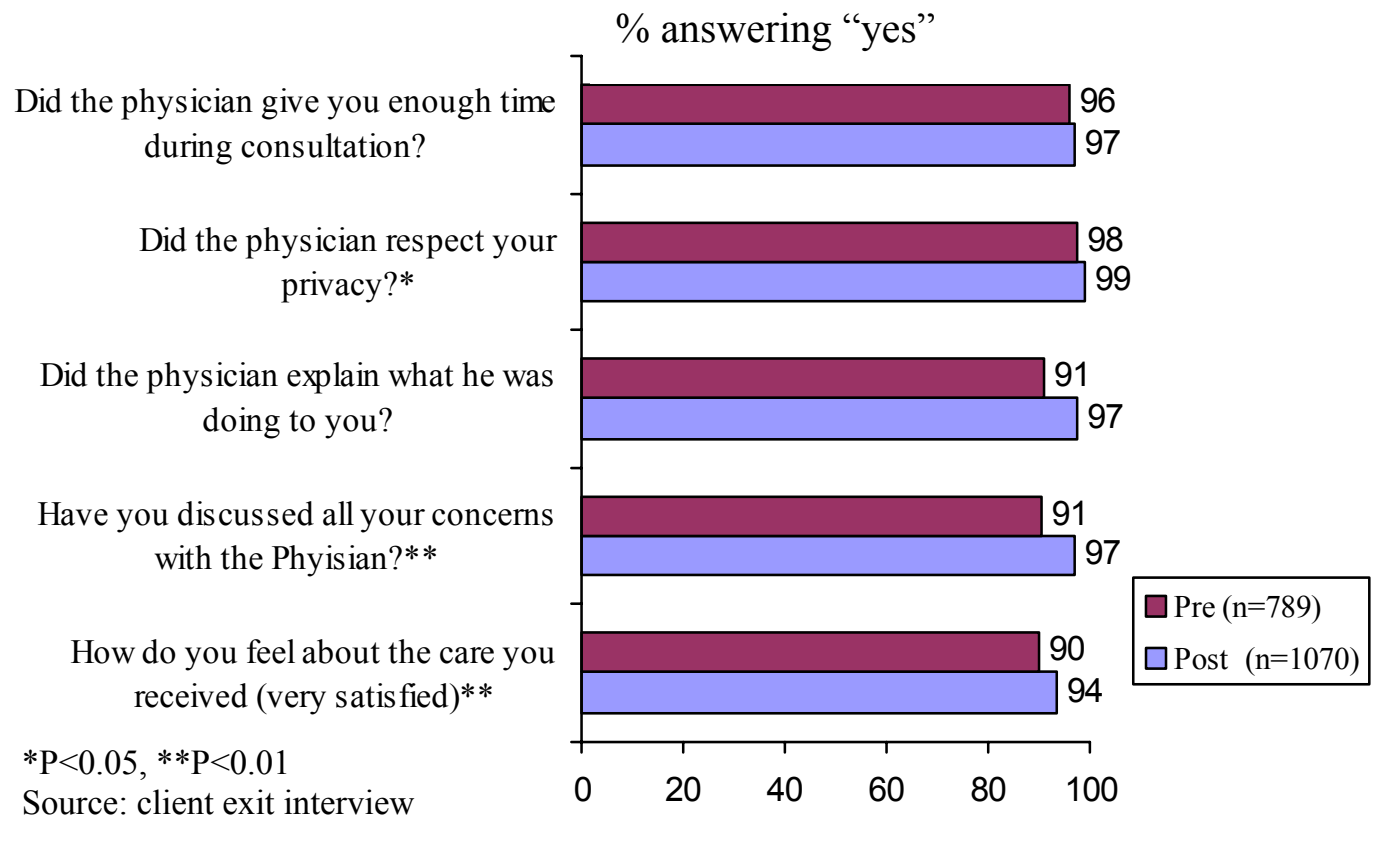

\section{Figure 11: Selected Indicators on Quality of Care}

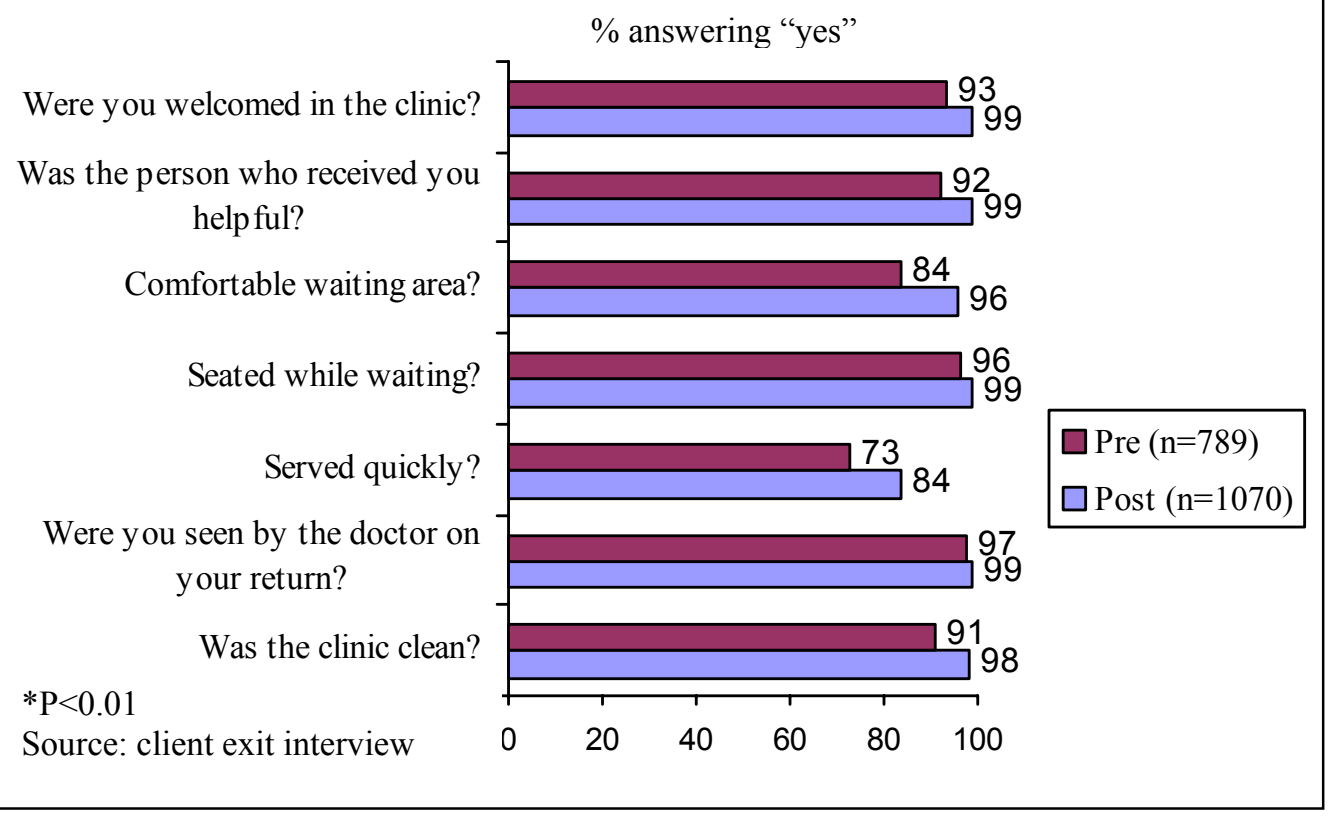




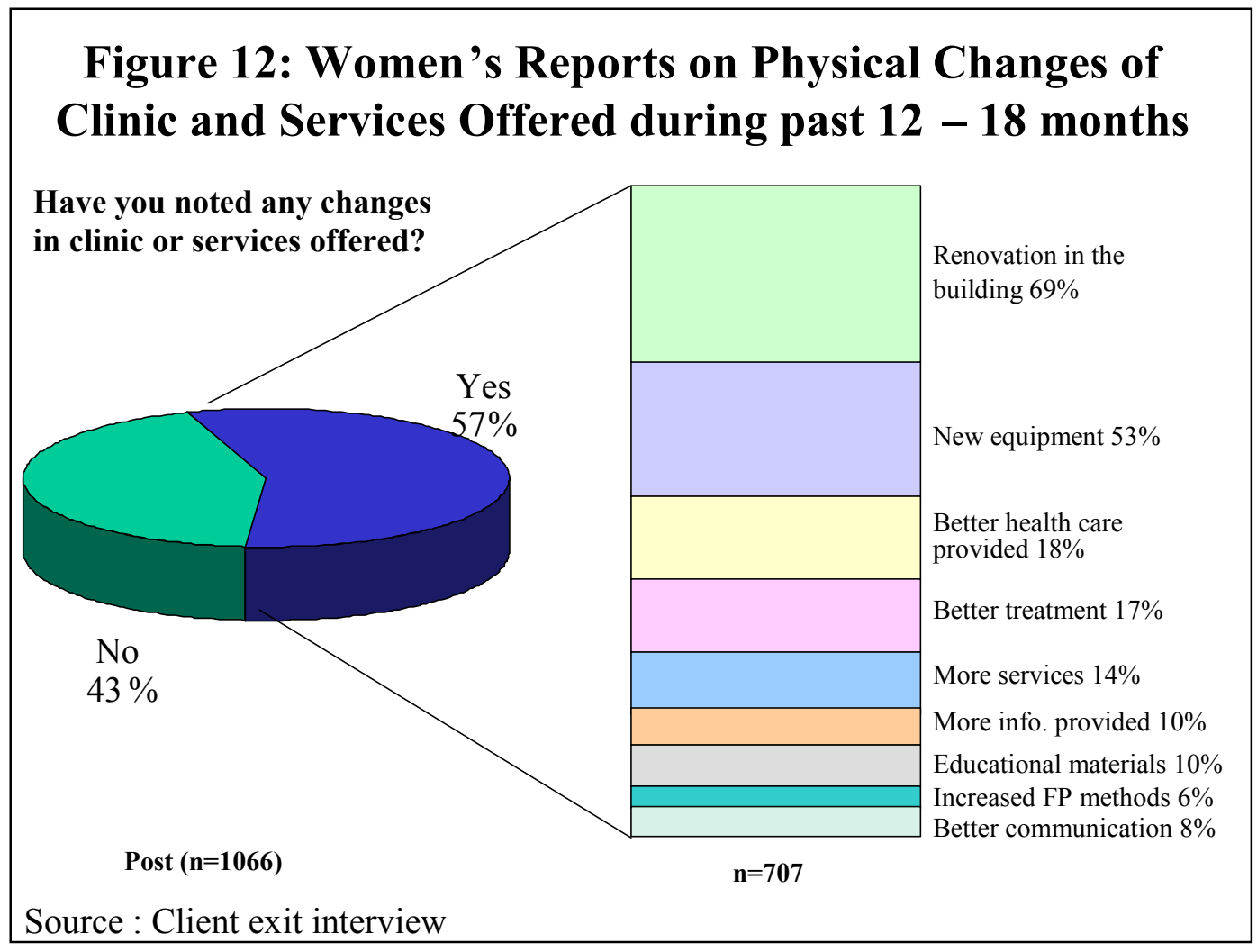




\section{OVERVIEW OF FINDINGS}

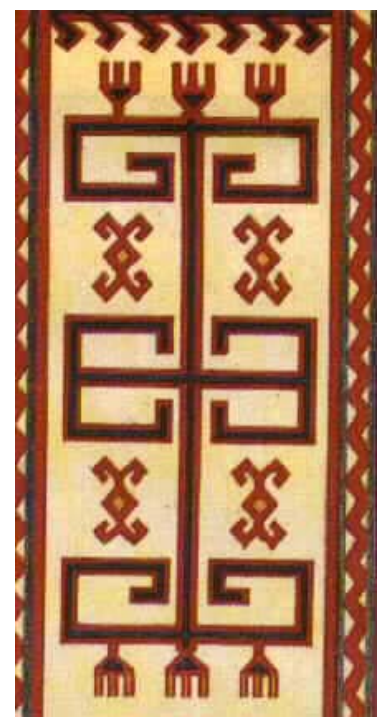

This study provides an overview of changes that occurred on the PHP's outcome indicators after launching the project's interventions. This 28 month project was aimed at improving the antenatal and postpartum services of the PHP clinics by upgrading the knowledge and skills of all cadres of service providers at PHP clinics as well as strengthening the health seeking behavior of Palestinian women. The lifetime of the PHP project was relatively short ( 28 months) to both institute and sustain complex interventions. The pre-test measurement was conducted between May and August 2000 and the post-test measurement was conducted between October and November 2001. This leaves only slightly more than a single year for PHP interventions to be in operation, which may not have been sufficient to demonstrate the full effects of the PHP interventions, or their sustained operations.

Furthermore, beyond this challenge lies a much more complex situation in which political unrest and deteriorating living conditions prevailed due to the onset of Al-Aqsa Intifada in September 2000. This situation caused complete closure of some of the Palestinian towns and villages and irregular work schedules of service providers. This situation, in turn, has influenced the possibility of carrying out the original work plans set for implementing activities, including home visits to postpartum women as well as health provider training schedules and formats. To a large extent, it has also caused a shift of focus of the health seeking behaviors of the target groups towards emergency services rather $\mathrm{MCH}$ services.

Despite the above conditions, the post-test findings provide evidence of improvements in several of the PHP outcome indicators, and in many areas the improvements have been remarkable.

1. There was a significant increase in the proportion of postpartum care and family planning visits between the pre- and post-test surveys. The proportion of postpartum visits doubled from 2.1 percent in the pre-test to 4.2 percent in the post-test.

Family planning visits increased by almost 2.5 fold between the two surveys. This indicates more awareness among women about the importance of these services for their own health and that of their newborn. The absolute number of postpartum visits remains quite low, despite the impressive gains achieved by the PHP.

\section{Among women who sought postpartum care, a larger proportion reported seeking care for themselves and their babies rather than for only the babies.}

Traditionally, postpartum services in the Palestinian context have focused on the newborn and offered little to the mother. The PHP changed this situation to some extent in the project's clinics. About 51 percent of women who came to PHP clinics to receive postpartum care during the post-test reported that they were seeking care for themselves, compared to 45 percent in the pre-test. Also, women who said they came to receive services for both themselves and their babies increased to 38 percent in post-test compared to 33 percent in pre-test. This indicates that women have found services at the PHP clinics 
that address their own postpartum needs, in addition to increased awareness of the importance of antenatal care for women.

3. Although the proportion of women in the post-test survey who reported receiving a home visit did not increase, the content of the visit improved substantially.

Results form the post-test survey only indicated that most of postpartum women who received a home visit reported that the visit was "very useful," and all of them indicated that the CHW encouraged them to make a return visit to the clinic on day 40. It is possible that many women did not receive a home visit because of closures and curfew imposed in many areas which restricted movement across areas.

4. The proportion of women in the post-test survey currently using any family planning method or a modern method more than doubled, and the proportion of low parity women (1-2 living children) currently using a contraceptive method also increased two-fold.

About 32 percent of the women reported current use of a family planning method in the post-test compared to only about $14 \%$ in the pre-test. Also, low parity women currently using any family planning method increased from only about 7 percent in the pre-test to about 29 percent in the post-test. All these differences are statistically significant and demonstrate how the PHP was able to respond to a large unmet need for family planning.

5. There has been modest or no improvement in the knowledge of antenatal and postpartum women about specific warning signs during ANC and PP periods and newborns' warning signs, yet the percentage of women who reported knowledge of the majority of warning sign items increased substantially.

Despite differential improvement (modest or no improvement) of women's knowledge about ANC and PP warning signs items, the percentage of antenatal women who reported knowledge of at least 10 antenatal warning sign items increased from 9 percent in the pretest to about 20 percent in the post-test. Also, the percentage of postpartum women reporting knowledge of at least five postpartum warning sign items increased from about 4 percent in the pre-test to about 24 percent in the post-test. These dramatic gains in complete and accurate knowledge are statistically significant. No similar improvements were observed in women's knowledge about newborns' warning signs.

6. Health-seeking practices among Palestinian women were found to be high in the pretest survey and remained strong throughout the PHP.

A range of antenatal women had experienced one or more of the ANC warning signs during their pregnancies (5-25\%). Almost all of these women (93\% in pre-test vs. $94 \%$ in post-test) sought treatment of this health condition, and about four-fifths received treatment. Also, despite the small number of cases of postpartum women, the findings from this study indicate that all women who experienced postpartum warning signs sought and received treatment.

7. A smaller proportion of women in the post-test survey reported being told by service providers how to conduct breast-self examination on a regular basis. Yet, of those who 
received this information, 60 percent of the women in the post-test reported that their source of knowledge was the PHP clinic compared to the pre-test (21\%). Additionally, more women in the post-test survey reported conducting this self-examination on a regular basis compared with pre-test survey (about $60 \%$ vs. $41 \%$ ). These differences are statistically significant and indicate a positive impact of the PHP.

Furthermore, the PHP increased the proportion of ANC women aged 35 years and older who reported ever receiving a pap smear: 18 percent in the post-test, compared with 11 percent in the pre-test.

8. Men continued to be involved in their wives' reproductive health. Husbands' beliefs in the importance of antenatal care of their wives and their encouragement for ANC visits were almost universal in both pre-test and post-test surveys.

Furthermore, an overwhelming majority of women in both surveys (92\%) reported discussing the use of family planning methods with their husbands. Almost all women reported that they agreed with their husbands on the decision to use family planning methods. However, there is some evidence that relatively more husbands and wives in the post-test prefer to wait for two years before having next child. In the pre-test, relatively more husbands and wives expressed preference to wait for three years. These results are not significant nor large enough to be meaningful but do suggest movement in changing deeply rooted cultural norms regarding spacing of births. Also, it is possible that the reported fertility preferences have been to some extent impacted by the September 2000 Intifada and the accompanying conditions including economic hardship and death among children and youth.

9. Technical knowledge and skills of service providers improved as a result of the PHP, yet there is still room for further improvement.

Substantially more antenatal women (72\%) reported in the post-test being asked by health providers about all of the nine obstetric history items, compared to only 39 percent in the pre-test.

Also, more antenatal and postpartum women reported in the post-test that health providers conducted a more complete health examination for them, compared with the pre-test. In addition, nurses and CHWs were more likely to provide more information items to new family planning clients in the post-test, compared with the pre-test.

However, the post-test findings show that there is still room for further improvements in service providers' skills and information given to antenatal and postpartum women.

10. These findings reveal that there was a general improvement in providing follow-up information on ANC and postpartum care to all PHP clients.

The percentage of ANC women who reported receiving information on all 12 of the ANC information items increased from less than 3 percent in the pre-test to 13 percent in the post-test. Also, the percentage of postpartum women reporting that they received all nine of the postpartum information items increased from less than 3 percent in the pre-test to 13 percent in the post-test. These differences are statistically significant and reveal that, despite impressive gains, there is still room for further improvements. 
11. Although baseline indicators of quality of care were already high, the PHP achieved positive gains. Of particular importance are the improvements made in clientprovider interaction indicators.

Also, most of clients noticed changes made at the clinic during the intervention period including clinic renovations, additional equipment procurement, additional services introduced and the BCC materials developed and distributed to clinic and clients. These changes encouraged more visits to PHP clinics (as reported by 94\% of women). 


\section{RECOMMENDATIONS}

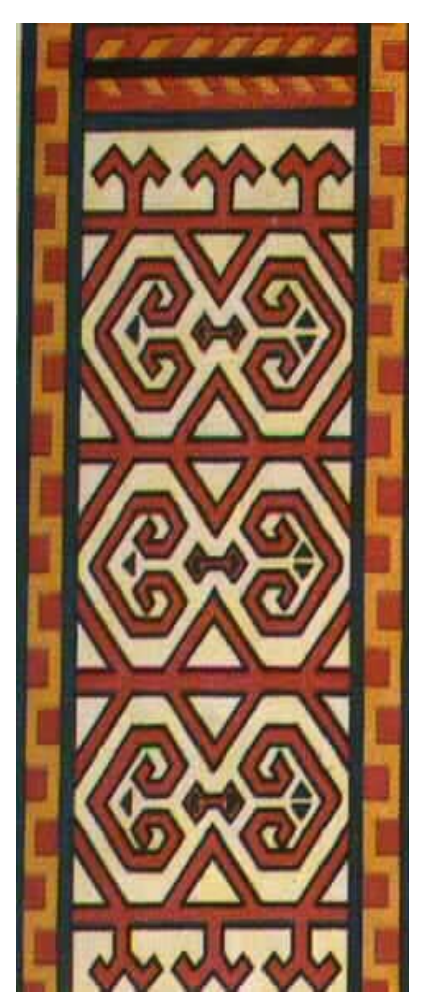

Based on the post-test findings, the PHP made improvements in the health- seeking behaviors of clients and enhanced providers' technical knowledge and clinical practices. However, one should keep in mind possible potential bias that might have been introduced due to the September 2000 Intifada and the accompanying deterioration of living conditions, difficult conditions on the roads as well as restricted movements across some Palestinian cities and villages.

Also, although it was not possible to recruit in the post-test survey the same data collectors who were engaged in the field operations of the pre-test survey, the same trainers were used in both pre-test and posttest surveys to train data collectors on the concepts used for the study objectives and questions included in the study instruments. In addition, the post-test survey utilized the same questions in its data collection instruments, and only added some new items to collect additional information on the PHP interventions. Thus, no or minimal bias may arise from this source.

Furthermore, the analysis on the socio-economic and demographic characteristics of the women who visited the PHP clinics during the pre-test and the post-test surveys have shown that those characteristics were very close in both surveys. Small, yet statistically significant differences in women's mean age and number of schooling years as well as mean age difference between husbands and wives were indicated. Although it is believed that these differences are of little substantive value, some minor bias might have been introduced to the extent that women interviewed in the pre-test and post-test surveys were different.

Despite improvements made by the PHP in the health -seeking behaviors of clients and enhancing providers' technical knowledge and clinical practices; there is still much to be done.

The following is a list of key recommendations to further improve the health status of Palestinian women and their children in the West Bank and Gaza Strip:

1. Even though return visits to clinics to receive postpartum care doubled during the PHP, the absolute numbers of postpartum women returning to PHP clinics is low. In addition to sustaining and increasing the basic package provided by PHP, some referral mechanisms should be worked out to promote wider coverage of essential postpartum care. One of the operations research studies ${ }^{15}$ conducted under the PHP assessed the feasibility of establishing outreach linkages with public hospitals to promote postpartum coverage. This study raised a number of sound recommendations that need to be followed up and implemented by the IVCHS project. This activity fits within the referral component "strengthening links between community, primary and secondary care" of its strategy related to "client-centered primary health care model." 
2. The continuous training of all categories of service providers needs to be emphasized to strengthen their capacity and skills. In addition, staffing patterns of $\mathrm{MCH}$ clinics need to be reviewed and adequate numbers of physicians and CHWs in charge need to be realistically determined. This is especially important in situations where physicians have to rotate daily among a number of clinics in different villages. Furthermore, the CHWs are often busy with a wide range of clinic-based activities, leaving scant time for outreach activities. The difficulties associated with transportation and the need for superlative supervision need to be addressed.

3. Both the pre-test and the post-test findings suggest that antenatal care-seeking is both common and desirable by Palestinian women. However, both women and their families need to be educated about the importance of postpartum care, including family planning for spacing purposes. Culturally sensitive health education messages that address these objectives need to be designed, and appropriate communication channels need to be tested.

4. Breast-self examination and cervical cancer screening require further integration into routine primary health care services. IVCHS programs need to build on activities launched under the PHP along this line. Coordination between MOH, NGOs and the private sector will be needed to help maximize achievements in the detection and treatment of cancer.

5. There is a need to promote the information given as part of ANC and PP services to women. Specifically, there is a need to strengthen the information on ANC, PP and newborn warning signs that warrant seeking immediate medical attention.

6. According to study results, three-fourths of Palestinian women rely on the IUD as their contraceptive method, which calls for wider method mix to expand contraceptive choice. Appropriate assessments may be done to promote condom acceptance for dual protection. 


\section{REFERENCES AND NOTES}

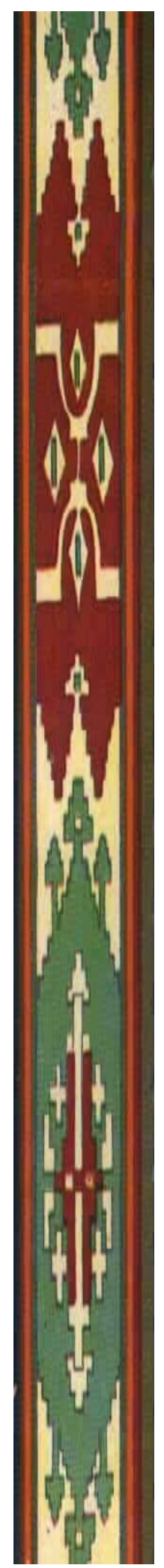

1. Palestinian Central Bureau of Statistics, 2000. "Health Survey 2000: Main Findings". Ramallah-Palestine.

2. World Health Organization, 1994. "Antenatal Care; Report of a Technical Working Group”. Geneva. (WHO/FRH/MSM/96.8).

3. Palestinian Central Bureau of Statistics, 1997. "The Health Survey in the West Bank and Gaza Strip: Main Findings". Ramallah, Palestine

4. Abdeen Z, Barguthi F., 1994. "Palestinian Cancer Statistics:

Seventeen Years of Cancer Incidence, 1967-1992". Ramallah: Arab College of Medical Professions, Al-Quds University.

5. Ministry of Health-HMIS. The Status of Health in Palestine 2000. July 2001.

6. El-Jabari, C., 1997. "The Prevalence of Breast Disease among Palestinian Women, 1994-1996”. Patients Friends Society, Palestine.

7. Wick, L., 1998. "The Pap Smear in the West Bank; Implications for a Women's Health Strategy in Palestine". Jerusalem: The Palestinian Coalition for Women's Health.

8. Partners include CARE International, The Population Council, the Patients Friends Society (PFS), the Union of Palestinian Medical Relief Committees (UPMRC), the Union of Health Work Committees (UHWC), the Health, Development, Information and Policy Institute (HDIP), and the Center for Development in Primary Health Care (CDPHC).

9. Palestinian Central Bureau of Statistics, 2000. "Health Survey-2000: Main Findings". Ramallah-Palestine.

10. Palestinian Central Bureau of Statistics, 2000. "Health Survey-2000: Main Findings". Ramallah-Palestine. (p.35, 96)

11. HDIP, forthcoming, "Creation of a Unified Management Information System for three NGOs in West Bank / Gaza"

12. Palestinian Central Bureau of Statistics, 2000. "Health Survey-2000: Main Findings. Ramallah-Palestine". Note: The figures represent the percentage distribution of the last two births in the last three years preceding the survey. 


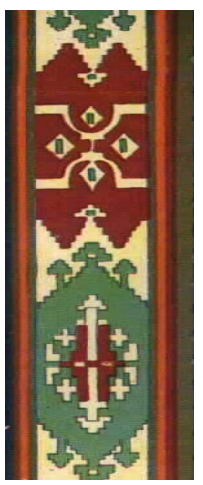

13. Center for Development in Primary Health Care (CDPHC), forthcoming, "Improving postpartum care among low parity mothers in Palestine", Palestine

14. HDIP, forthcoming, "Involving Men in the Wives' Postpartum Care in Palestine".

15. HDIP, forthcoming, "Outreach Linkages with Public Hospitals to Promote Postpartum Care".

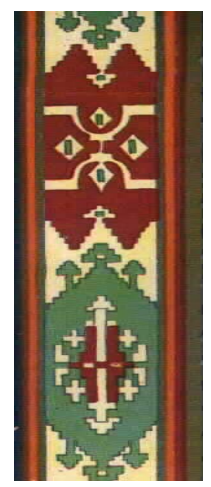

